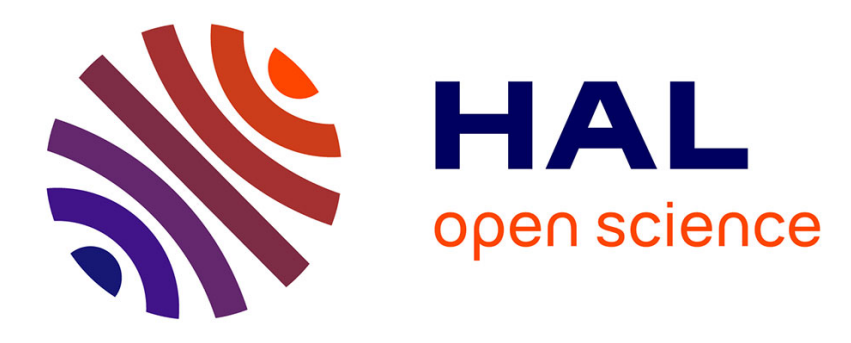

\title{
Thermal ageing of a silane-crosslinked polyethylene stabilised with an excess of Irganox 1076
}

\author{
Anne Xu, Sébastien Roland, Xavier Colin
}

\section{To cite this version:}

Anne Xu, Sébastien Roland, Xavier Colin. Thermal ageing of a silane-crosslinked polyethylene stabilised with an excess of Irganox 1076 . Polymer Degradation and Stability, 2021, 189, pp.109597. 10.1016/j.polymdegradstab.2021.109597 . hal-03262685

\section{HAL Id: hal-03262685 \\ https://hal.science/hal-03262685}

Submitted on 16 Jun 2021

HAL is a multi-disciplinary open access archive for the deposit and dissemination of scientific research documents, whether they are published or not. The documents may come from teaching and research institutions in France or abroad, or from public or private research centers.
L'archive ouverte pluridisciplinaire HAL, est destinée au dépôt et à la diffusion de documents scientifiques de niveau recherche, publiés ou non, émanant des établissements d'enseignement et de recherche français ou étrangers, des laboratoires publics ou privés. 


\title{
Thermal ageing of a silane-crosslinked polyethylene stabilised with an excess of Irganox $1076^{\circledR}$
}

\author{
Anne Xu, Sébastien Roland, Xavier Colin* \\ PIMM, Arts et Métiers Institute of Technology, CNRS, CNAM, HESAM University, 151 boulevard de l'Hôpital, 75013 Paris, France
}

\begin{abstract}
A B S T R A C T
This work focuses on the thermal ageing in air of a silane-crosslinked polyethylene stabilised with an excess of phenolic antioxidant (Irganox $1076 \AA$ ) in the temperature range between $87^{\circ} \mathrm{C}$ and $130^{\circ} \mathrm{C}$. In such case, it was shown in previous works that the antioxidant is present in two physical states: dissolved in the polymer matrix and exuded at the sample surface under the form of crystals. The purpose was, in particular, to investigate the role of an antioxidant excess in the stabilisation process of the polymer. On this purpose, the pure antioxidant crystals (i.e. the commercial powder) and a polymer sample stabilised with only dissolved antioxidants (i.e. in a concentration lower than the solubility threshold) were investigated at $130^{\circ} \mathrm{C}$ to isolate and elucidate the thermal ageing behaviour of each antioxidant phase. For all the three studied samples, quinone methide and cinnamate species were formed through the chemical consumption of antioxidants. For both stabilised samples (with an excess, or not, of antioxidants), similar behaviours were observed in term of antioxidant depletion. In particular, it was shown that although some chemical consumption was also detected, the initial antioxidant depletion was essentially due to its physical loss through evaporation. In addition, in both cases, the polymer oxidation was observed after the almost total depletion of antioxidants and without any additional oxidation induction period. The comparison of the oxidation induction periods obtained at $130^{\circ} \mathrm{C}$ for these two samples showed that the antioxidant excess efficiently participates to polymer stabilisation during thermal ageing, which could be due to a further solubilisation of antioxidants during thermal exposure.
\end{abstract}

\section{Introduction}

Crosslinked low density polyethylene (XLPE) is one of the most widely used polymers for the insulation of electrical cables in the reactor buildings of nuclear power plants (NPP). In this type of application, XLPE is subjected to the combined effects of irradiation and temperature. Under normal service conditions, the dose rate is typically ranged between $10^{-2}$ and $10^{-1}$ Gy.h ${ }^{-1}$ and the temperature is about $30-50^{\circ} \mathrm{C}$. However, under severe accidental conditions, e.g. in the event of a loss of primary coolant accident, the dose rate and the temperature can rise up to $10^{5} \mathrm{~Gy} \cdot \mathrm{h}^{-1}$ and $150^{\circ} \mathrm{C}$, respectively [1]. In order to guarantee the control and safety of NPP under both normal and accidental conditions, it is hence crucial to check the long-term resistance to radio-thermal ageing of XLPE insulation.

As any hydrocarbon polymer, XLPE is sensitive to radical chain oxidation which, in a nuclear environment, can be initiated both by ionizing radiations [2-5] and temperature [6-10]. In fact, oxidative

\footnotetext{
* Corresponding author.

E-mail address: xavier.colin@ensam.eu (X. Colin).
}

degradation is susceptible to occur at all stages of the polymer lifecycle (from its synthesis up to its in-service use, including its processing) and results into irreversible modifications of the polymer chemical composition, leading, more or less directly, to a loss of the polymer macroscopic properties. In particular, it is often considered that the loss of insulating properties is due both to the formation of more polar species (i.e. oxidation products) and the increase in water absorption [11,12]. In contrast, mechanical embrittlement results essentially from chain scissions and chemicrystallisation phenomenon [13,14].

In order to protect the polymers against oxidative degradation and ensure their long-term stability, a low concentration of antioxidants (AO) is generally incorporated into polymers during the first steps of their processing operation. Different types of AO exist, which mainly differ from their general chemical structure and their stabilisation mechanism. Two main types of AO are commonly used for NPP applications [15-17]: free radicals scavengers (also often called primary AO), and hydroperoxides decomposers. Among the primary AO, hindered phenols, such as octadecyl-3-(3,5-di-tertbutyl-4-hydroxyphenyl)propionate, well-known as Irganox 1076®, have long been known to be effective against thermal oxidation in 


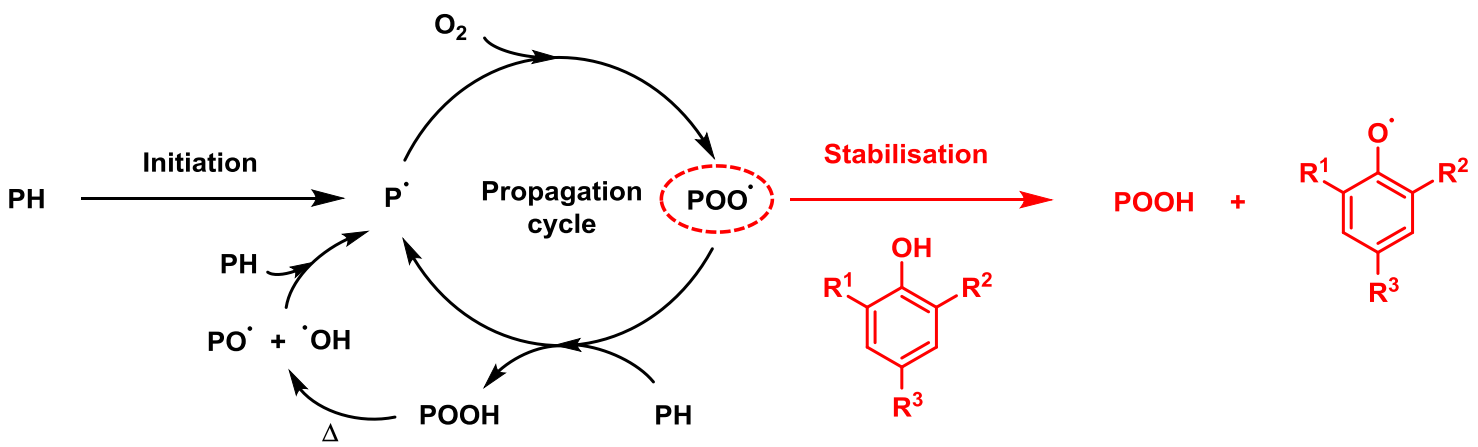

Fig. 1. Simplified mechanistic scheme for the radio-thermal oxidation of a polyolefin stabilised by a hindered phenol antioxidant [18,23-26].

polyolefins in a large temperature range [18-22]. Their stabilisation mechanism stems from the H-donor character of the phenol function of AO, i.e. its great facility to give up its $\mathrm{H}$ atom to a free radical, which induces the termination of peroxyl radicals $\left(\mathrm{POO}^{\circ}\right)$ generated by the polymer oxidation reaction [18,23-26], as shown in Fig. 1.

However, due to their significant difference in polarity, the solubility of hindered phenols in polyolefins is generally low, typically less than $1 \mathrm{wt} \%$ in polyethylene (PE) $[17,27,28]$. Due to this limited solubility, an oversaturation can easily occur in industrially formulated polyolefins. In fact, AO are generally incorporated into polymers during the processing operation at high temperatures in melt state, i.e. in conditions where AO are usually highly soluble in polymers. However, during cooling, as the polymer crystallises and the AO solubility in the amorphous phase decreases with temperature, the polymer can rapidly become supersaturated in AO, leading to several phenomena such as a phase separation of $A O$ from the polymer matrix, and the exudation and blooming of $\mathrm{AO}$ at the sample surface [29-32].

In our previous studies on a PE-based material stabilised with different concentrations of Irganox $1076 \AA[29,33]$, a phase separation was detected above a threshold concentration of $\mathrm{AO}$ of about 0.9 wt\% (i.e. $\approx 1.6 \times 10^{-2} \mathrm{~mol} . \mathrm{L}^{-1}$ ) at ambient temperature. In particular, it was shown that $\mathrm{AO}$ in excess were under the form of crystals and only present onto the sample surface. Thus, two different situations were distinguished depending on the AO concentration. When the $\mathrm{AO}$ concentration $[\mathrm{AO}]$ is below or equal to the threshold concentration (noted $[A O]_{C}$ ), the stabilisation is considered homogeneous because all AO are dissolved in the polymer matrix. In contrast, when $[A O]$ is above $[A O]_{c}$, the stabilisation is considered heterogeneous because the polymer matrix is fully saturated with dissolved AO but, in addition, AO in excess are exuded and crystallised at the sample surface. The question that naturally arises is: do AO crystals also contribute to the polymer stabilisation under the different exposure conditions of a nuclear environment?

The present study aims at investigating the stabilisation efficiency by Irganox 1076 ${ }^{\circledR}$ in a heterogeneously stabilised silanecrosslinked polyethylene (Si-XLPE) during its thermal ageing in air at three different temperatures: $87^{\circ} \mathrm{C}, 110^{\circ} \mathrm{C}$, and $130^{\circ} \mathrm{C}$. The analyses will be performed using the same experimental methodology established in our previous publications [29,33]. Given the microstructural complexity of this material, the first stage will consist in isolating and elucidating the thermal ageing behaviour of its two constitutive phases (i.e. AO crystals and homogeneously stabilised Si-XLPE matrix) by additionally examining three model materials in turn (as schematically represented in Fig. 2): i) the as-received Irganox $1076 \AA$ powder; ii) a Si-XLPE sample stabilised with 0.6 wt\% of Irganox 1076® (i.e. below the threshold concentration of $0.9 \mathrm{wt} \%)$; iii) the pure Si-XLPE matrix. This first stage is necessary not only to determine the ageing mechanisms in each phase, but also to deduce the possible additional ageing mechanisms operating in the more complex material under study. Then, the study of the thermal ageing of the heterogeneously stabilised sample will enable to check the reliability of the previous ageing mechanisms in the more complex material, and to investigate the stabilisation efficiency by antioxidants in excess (crystals).

\section{Materials and methods}

\section{1. $\mathrm{KBr}$ disc with Irganox $1076 \circledR$}

The commercial Irganox 1076® (whose chemical structure is shown in Fig. 3) was supplied by Sigma Aldrich under the form of a white powder. It should be mentioned that some physicochemical characteristics of the as-received commercial powder were already determined and discussed in our previous work [29]. In particular, it was shown that its crystalline structure (i.e. form I) is the same than the AO crystals exuded at the surface of the heterogeneously stabilised samples.

The thin $\mathrm{KBr}$ disc was prepared by mixing $100 \mathrm{mg}$ of $\mathrm{KBr}$ powder with $1 \mathrm{mg}$ of Irganox $1076 \AA$ powder. The resulting mixture was grinded into a fine powder using a mortar then compressed for 5 minutes under $4 \mathrm{MPa}$ to obtain the $\mathrm{KBr}$ disc.

\subsection{Films of silane-crosslinked polyethylene stabilised with Irganox $1076 \circledR$}

Films of silane-crosslinked polyethylene (Si-XLPE) of about 600 $\mu \mathrm{m}$ thick containing about $0.6 \mathrm{wt} \%$ and $2.1 \mathrm{wt} \%$ of Irganox $1076 \AA$ were gratefully provided by Nexans. These films were respectively produced by hot-compression and extrusion moulding from pellets of a linear low-density polyethylene grafted with a vinyl trimethoxy silane (Si-g-LLDPE). The crosslinking of the polymer was performed by immersion in water at $65^{\circ} \mathrm{C}$ for 48 hours. The density, crystallinity ratio and gel content of the resulting Si-XLPE are about 0.918 g.cm ${ }^{-3}, 41 \%$, and $71 \%$, respectively.

It should be mentioned that the pellets of Si-g-LLDPE already contained a small amount of storage AO (about $0.1 \mathrm{wt} \%$ ), mainly BHT and Irganox 1076®, prior to the addition of Irganox 1076® during the processing operation [29]. These storage AO were considered for the calculation of the total concentration of $\mathrm{AO}$ in the Si-XLPE films, thus inducing a slight difference between the total concentrations of ester and phenol functions.

All films were stored at ambient temperature in a desiccator containing silica gel before any physico-chemical characterization.

\subsection{Surface cleaning treatment}

The surface of the heterogeneously stabilised Si-XLPE films were gently cleaned with absorbing paper and acetone as polar 


\section{Material under study}

AO crystals (polymer surface)

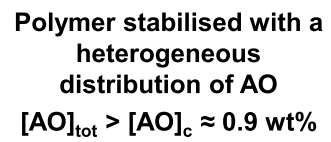

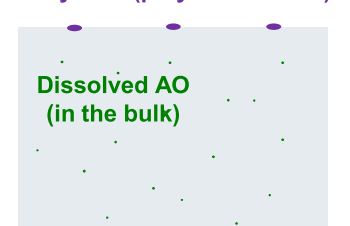

Polymer

$[\mathrm{AO}]_{\text {tot }}=[\mathrm{AO}]_{\mathrm{c}}+[\mathrm{AO}]_{\text {insol }}$
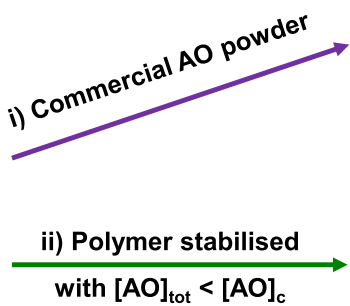

with $[\mathrm{AO}]_{\mathrm{tot}}<[\mathrm{AO}]_{\mathrm{c}}$

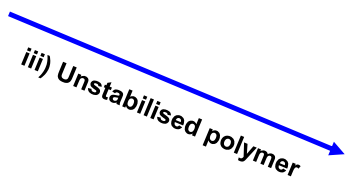

SESE:

Pure AO crystals

$[\mathrm{AO}]_{\mathrm{tot}}=[\mathrm{AO}]_{\mathrm{insol}}$
Dissolved AO

(in the bulk)

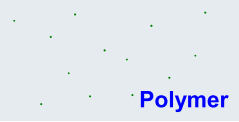

$[\mathrm{AO}]_{\text {tot }}=[\mathrm{AO}]_{\mathrm{sol}}$

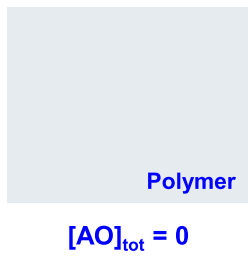

Polymer stabilised

with a homogeneous distribution of $\mathrm{AO}$
Polymer matrix alone

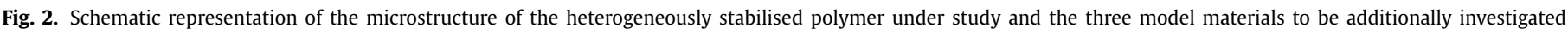
in order to elucidate the ageing mechanisms. $[\mathrm{AO}]_{\mathrm{c}}$ corresponds to the solubility threshold of $\mathrm{AO}$ in the polymer matrix.<smiles>CCCCCCCCCC(=O)OCCCc1cc(C(C)(C)C)c(O)c(C(C)(C)C)c1</smiles>

Fig. 3. Chemical structure of Irganox $1076 \circledast$

solvent (supplied by Sigma-Aldrich) in order to remove all AO crystals present on their surface without changing the concentration of the AO dissolved in their bulk, as previously shown in reference [33]. Thanks to this surface cleaning, it was possible to deconvolve the physico-chemical responses of dissolved and crystallised AO.

\subsection{Ageing conditions}

All the thermal ageing experiments were performed in airventilated thermal ovens. The pure Irganox $1076 \circledast$ powder (in $\mathrm{KBr}$ disc) and the Si-XLPE film stabilised with $0.6 \mathrm{wt} \%$ of Irganox $1076{ }^{\circledR}$ were only thermally aged at $130^{\circ} \mathrm{C}$. In contrast, the Si-XLPE film stabilised with $2.1 \mathrm{wt} \%$ of Irganox $1076 \AA$ was exposed to three different temperatures of ageing: $87^{\circ} \mathrm{C}, 110^{\circ} \mathrm{C}$, and $130^{\circ} \mathrm{C}$. It should also be mentioned that an almost pure Si-XLPE film, i.e. produced from pellets of Si-g-LLDPE without the addition of Irganox 1076®, was also aged under the same exposure conditions as a control sample.

For each ageing temperature, samples were removed regularly from ovens and cooled to room temperature in the dry atmosphere of a desiccator before being analysed by complementary physicochemical characterisation techniques.

\subsection{Fourier-Transform Infrared (FTIR) spectroscopy}

This technique was used to monitor the modifications of the samples chemical composition. In particular, FTIR spectroscopy was used to identify and quantify the different AO phases (dissolved and crystallised) and the oxidation products (from AO and the polymer matrix) detected during the thermal exposure in air. For these purposes, this technique was used in two different modes: Attenuated Total Reflectance (ATR) mode and transmission mode. In fact, in ATR mode, the penetration depth of the IR radiation in PE samples is generally ranged between 0.2 and $1.3 \mu \mathrm{m}$, for a wavenumber typically varying from 4000 to $650 \mathrm{~cm}^{-1}$ [29]. Therefore, in ATR mode, mainly the surface of the polymer films is analysed. In contrast, in transmission mode, the sample is analysed throughout its whole thickness (i.e. both the surface and the bulk). With regard to AO, in ATR mode, mainly the IR signature of the AO crystals present on the sample surface is detected, while in transmission mode, both the IR signatures of dissolved and crystallised AO can be observed.

Previous works have indeed shown that FTIR spectroscopy is a very efficient technique to identify the physical state (i.e. dissolved or crystallised) of AO in PE-based materials [29,33], but also to distinguish the different polymorphic forms of AO crystals [29,31] as, in each case, a specific IR signature can be observed by FTIR spectroscopy. The position of the IR absorption bands of interest of AO and their attribution, depending on the physical state or the crystalline structure of $\mathrm{AO}$, are compiled in Table 1.

Table 1

IR absorption bands of Irganox 1076® and their attribution [29,31,33].

\begin{tabular}{ll}
\hline Attribution & Wavenumber $\left(\mathrm{cm}^{-1}\right)$ \\
\hline In “dispersed state" & $3648-3649(\mathrm{O}-\mathrm{H}$ of phenol) \\
(i.e. dissolved in PE) & $1740-1741(\mathrm{C}=\mathrm{O}$ of ester) \\
Crystalline Form I & $3639-3642(\mathrm{O}-\mathrm{H}$ of phenol) \\
& $1733-1736(\mathrm{C}=\mathrm{O}$ of ester $)$ \\
& $1279(\mathrm{C}-\mathrm{O}$ of ester $)$ \\
Crystalline Form II & $3590(\mathrm{O}-\mathrm{H}$ of phenol) \\
& $1723-1726(\mathrm{C}=\mathrm{O}$ of ester $)$ \\
Crystalline Form III & $1288(\mathrm{C}-\mathrm{O}$ of ester $)$ \\
& $3609-3612(\mathrm{O}-\mathrm{H}$ of phenol) \\
& $1720-1723(\mathrm{C}=\mathrm{O}$ of ester $)$ \\
\hline
\end{tabular}


When performed in transmission mode, FTIR spectroscopy can be used to estimate the concentration of chemical species using the Beer-Lambert's law, which can be written as follows:

$\mathbf{A}=\boldsymbol{\varepsilon} \times \mathbf{e} \times \mathbf{C}$

Where $\mathbf{A}$ is the absorbance, $\mathbf{e}$ the sample thickness $(\mathrm{cm}), \mathbf{C}$ the concentration of the absorbing species (mol.L ${ }^{-1}$ ), and $\boldsymbol{\varepsilon}$ the molar extinction coefficient $\left(\mathrm{L} \cdot \mathrm{mol}^{-1} \cdot \mathrm{cm}^{-1}\right)$. AO in the Si-XLPE films were titrated using the FTIR calibration curves established both for the phenol and ester functions of Irganox 1076® in our previous studies $[29,33]$. Moreover, AO oxidation products were quantified using molar extinction coefficients from literature. Their values will be given later in the results and discussion section.

FTIR spectra were recorded at room temperature using a Perkin Elmer FTIR Frontier spectrometer from 4000 to $650 \mathrm{~cm}^{-1}$ in ATR mode, and from 4000 to $400 \mathrm{~cm}^{-1}$ in transmission mode, after averaging the 16 scans obtained with a minimum resolution of $4 \mathrm{~cm}^{-1}$. In the case of ATR mode, the analyses were performed with a diamond/ZnSe crystal. Moreover, in order to better monitor all the chemical and physical modifications throughout thermal ageing, the FTIR spectra obtained in ATR mode were normalised with the absorbance of the $\mathrm{CH}_{2}$ scissoring vibrations at $1472 \mathrm{~cm}^{-1}$ assigned to the PE crystal phase [34]. In contrast, the FTIR spectra obtained in transmission mode were only normalised with the films thickness.

\subsection{Ultraviolet spectroscopy (UV)}

This technique was used as a complementary technique of FTIR spectroscopy to monitor the AO depletion and the formation of its main oxidation products during the thermal exposure in air.

Indeed, the phenol function of Irganox $1076 \AA$ can be detected around $270-280 \mathrm{~nm}$, as reported in the literature [35], while its main oxidation products can be detected around 300-320 nm [36]. As for FTIR spectroscopy, the Beer-lambert's law (Eq. 1) can also be applied in UV spectroscopy to quantify the chemical species. The main interest of this technique lies in the fact that the molar extinction coefficients for $\mathrm{AO}$ and its oxidation products are generally higher in UV than in IR, thus allowing a better detection in UV, even at low concentrations. However, for the same reason, the UV absorption bands of interest can be more easily saturated, in particular when high concentrations are concerned. For the titration by UV spectroscopy, the molar extinction coefficients were taken from literature. Their values will be given later in the results and discussion section.

UV spectra were recorded at room temperature using a Perkin Elmer Lambda 35 UV-Visible spectrometer from 200 to $400 \mathrm{~nm}$ with a scanning rate of $60 \mathrm{~nm} \cdot \mathrm{min}^{-1}$ in transmission mode.

\subsection{Differential Scanning Calorimetry under $\mathrm{O}_{2}$ (OIT measurements)}

This technique was used to measure the oxidation induction time (OIT) at a given temperature of the stabilised Si-XLPE films throughout their thermal exposure in air, which gives an estimation of the global concentration of active AO in PE-based materials $[33,37]$. Such a correlation can be written as follows:

$\operatorname{OIT}(\mathrm{T})=\mathrm{K}_{\mathrm{T}} \times[\mathrm{AO}]+\mathrm{OIT}_{0}(\mathrm{~T})$

Where $\mathbf{K}_{\mathbf{T}}$ is a constant only depending on the temperature $\mathbf{T}$ and the couple \{polymer matrix, AO\} under consideration, [AO] the concentration of the active functions of AO (here phenols), and $\operatorname{OIT}(\mathbf{T})$ and $\operatorname{OIT}_{\mathbf{0}}(\mathrm{T})$ the values of OIT at the measurement temperature for the stabilised and non-stabilised polymer matrix, respectively. For the pure Si-XLPE matrix, $\mathrm{OIT}_{0}$ is near zero in pure $\mathrm{O}_{2}$ atmosphere at $205^{\circ} \mathrm{C}$.
Table 2

Melting properties of Irganox 1076® depending on its crystalline structure [29,31,38].

\begin{tabular}{llll}
\hline Crystalline form of Irganox 1076® & Form I & Form II & Form III \\
\hline Melting point ( $\left.{ }^{\circ} \mathbf{C}\right)$ & $51 \pm 1$ & $51 \pm 1$ & $47 \pm 1$ \\
$\Delta \mathbf{H}_{\infty, \mathbf{A O}}\left(\mathbf{J . g}^{-\mathbf{1}}\right.$ ) & $120 \pm 3$ & $123 \pm 4$ & $142 \pm 9$ \\
$\boldsymbol{\Delta} \mathbf{H}_{\infty, \mathbf{A O}}\left(\mathbf{k J . m o l}{ }^{-\mathbf{1}}\right.$ ) & $64 \pm 2$ & $65 \pm 2$ & $75 \pm 5$ \\
\hline
\end{tabular}

OIT measurements were performed under a pure $\mathrm{O}_{2}$ flow at $205^{\circ} \mathrm{C}$ using TA Instrument DSC Q10 and Q20 calorimeters. This temperature was chosen in order to have an acceptable duration of experiments for both the unaged and aged samples. Samples of about $5 \mathrm{mg}$ were introduced in open standard aluminium pans. The samples were first heated under pure $\mathrm{N}_{2}$ flow ( $50 \mathrm{~mL} \cdot \mathrm{min}^{-1}$ ) from room temperature to $205^{\circ} \mathrm{C}$, at a heating rate of $10^{\circ} \mathrm{C} \cdot \mathrm{min}^{-1}$. After an isotherm segment of $5 \mathrm{~min}$ for temperature equilibration, the gas flow was switched from $\mathrm{N}_{2}$ to $\mathrm{O}_{2}$. An isotherm at $205^{\circ} \mathrm{C}$ was then performed under pure $\mathrm{O}_{2}$ flow $\left(50 \mathrm{~mL} \cdot \mathrm{min}^{-1}\right)$ in order to access the oxidation induction time (OIT) at this temperature. The OIT value was determined using the tangent method, which corresponds to the duration period between the introduction of the $\mathrm{O}_{2}$ flow in the DSC cavity and the onset of the oxidation exotherm.

\subsection{Differential Scanning Calorimetry under $\mathrm{N}_{2}$ (DSC measurements)}

This technique was used for detecting and quantifying the AO crystals in all samples (i.e. Irganox 1076® powder and Si-XLPE films), but also for monitoring the consequences of oxidation on the crystallinity ratio of the polymer matrix.

In our previous studies $[29,33,37]$, it was shown that AO crystals can also be easily detected by DSC analysis, due to the presence of their melting peak around $50^{\circ} \mathrm{C}$ on the DSC thermograms. Then, knowing the melting enthalpy of AO crystals, it is possible to estimate the concentration of insoluble AO in the polymer films using the following equation:

$[\mathrm{AO}]_{\text {insol }}=\frac{\Delta \mathrm{H}_{\mathrm{m}, \mathrm{AO}, \text { polymer }}}{\Delta \mathrm{H}_{\infty, \mathrm{AO}}} \times \rho_{\mathrm{PE}}$

Where $\rho_{\mathbf{P E}}$ is the polymer density $\left(0.918\right.$ g.cm $\left.{ }^{-3}\right)$, $\Delta \mathbf{H}_{\mathrm{m}, \mathrm{AO} \text {,polymer }}$ the melting enthalpy of AO crystals in the polymer sample under study $\left({\mathrm{J} . \mathrm{g}^{-1}}^{-1}\right.$, and $\mathbf{\Delta} \mathbf{H}_{\infty, \mathbf{A O}}$ the melting enthalpy of pure AO crystal $\left(\mathrm{kJ} \cdot \mathrm{mol}^{-1}\right)$. As previously recalled, Irganox $1076 \AA$ can undergo polymorphism, and each polymorph has specific physico-chemical properties. In particular, the melting properties of the three possible crystalline forms of Irganox 1076® are compiled in Table $2[29,31,38]$.

On the other hand, the crystallinity ratio $\left(\chi_{\mathbf{c}}\right)$ of Si-XLPE can be determined from the area under the corresponding melting peak in the DSC thermogram using the common following equation:

$\chi_{\mathrm{c}}=\frac{\Delta \mathrm{H}_{\mathrm{m}}}{\Delta \mathrm{H}_{\infty}}$

Where $\Delta \mathbf{H}_{\mathbf{m}}$ and $\Delta \mathbf{H}_{\infty}$ are the melting enthalpies (expressed in $\mathrm{J.g}^{-1}$ ) of the sample under investigation and the PE crystal, respectively. In literature, the commonly used value for $\Delta \mathrm{H}_{\infty}$ is $290 \mathrm{J.g}{ }^{-1}$ $[39,40]$.

DSC thermograms were recorded using a TA instrument DSC Q1000 calorimeter beforehand calibrated with an indium reference. The DSC experiments were performed on samples with a mass ranged between 5 and $8 \mathrm{mg}$ introduced in closed standard aluminium pans. The analyses were performed under a pure $\mathrm{N}_{2}$ flow of $50 \mathrm{~mL} . \mathrm{min}^{-1}$, in the temperature range between $-50^{\circ} \mathrm{C}$ and $250^{\circ} \mathrm{C}$, with heating and cooling rates of $10^{\circ} \mathrm{C} \cdot \mathrm{min}^{-1}$. 


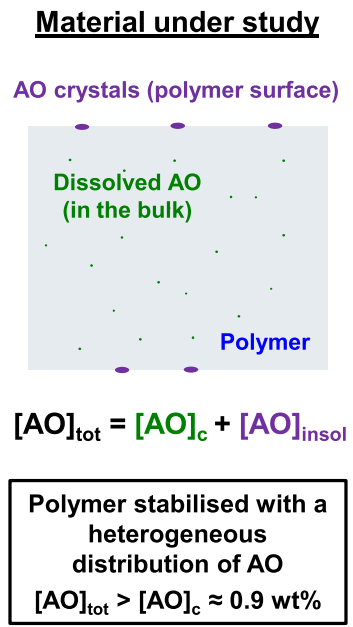

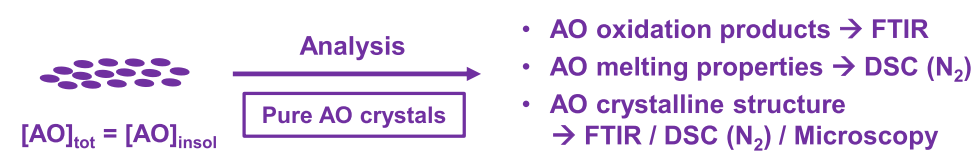

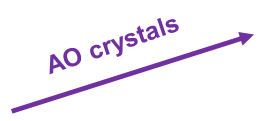

$[\mathrm{AO}]_{\text {tot }}=[\mathrm{AO}]_{\text {inso }}$ $\rightarrow$ FTIR / DSC $\left(\mathrm{N}_{2}\right)$ / Microscopy
Dissolved AO

(in the bulk)
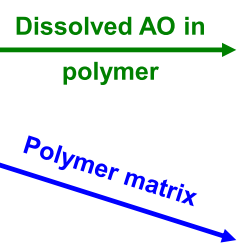

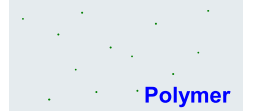

$[\mathrm{AO}]_{\text {tot }}=[\mathrm{AO}]_{\mathrm{sol}}$

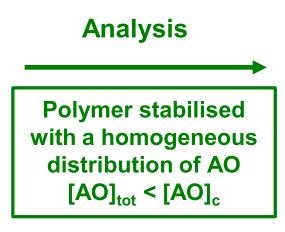

Analysis

Unstabilised polymer
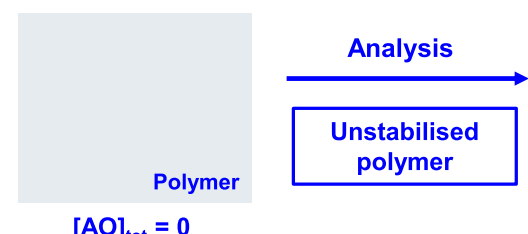

- Polymer oxidation products $\rightarrow$ FTIR

- Polymer crystallinity $\rightarrow$ DSC $\left(\mathrm{N}_{2}\right)$

\section{- Active AO $\rightarrow$ FTIR / UV / OIT}

- AO oxidation products $\rightarrow$ FTIR / UV

$[\mathrm{AO}]_{\text {tot }}=0$

Fig. 4. General experimental methodology used in this work.
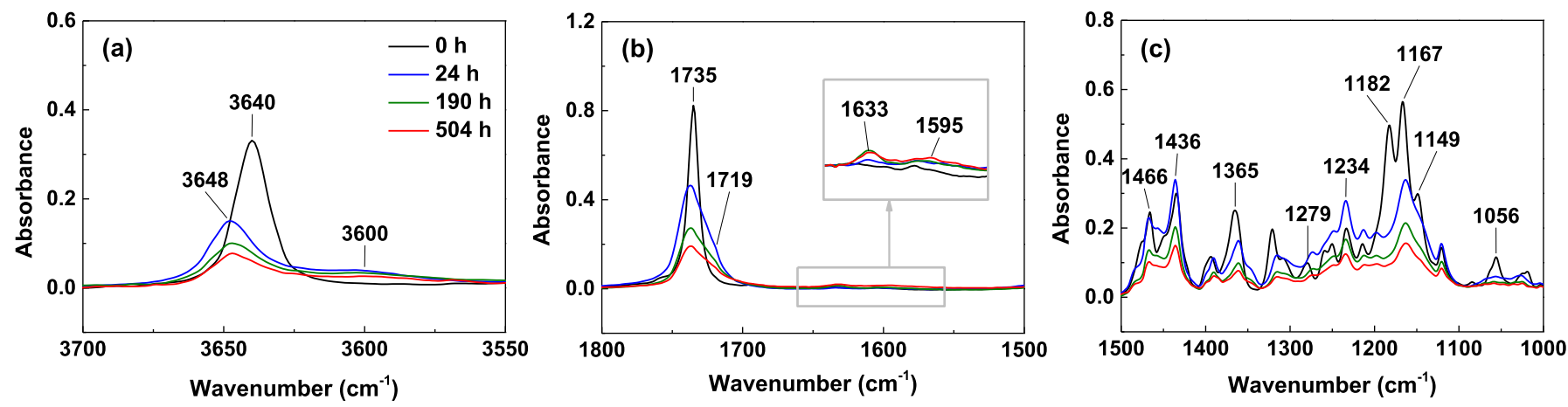

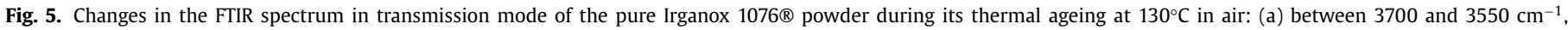
(b) between $1800-1500 \mathrm{~cm}^{-1}$, and (c) between $1500-1000 \mathrm{~cm}^{-1}$.

\subsection{Optical microscopy}

This technique was used to observe the surface of the Si-XLPE films. It is thus complementary to FTIR spectroscopy in ATR mode and DSC analysis under $\mathrm{N}_{2}$ in order to confirm the presence, or absence, of AO crystals.

The surface of the Si-XLPE films was examined before and after acetone cleaning using a Zeiss Axio Imager 2 optical microscope. The microscopic observations were performed in reflection mode with a polarised light.

The general experimental methodology used for this study is summarised in Fig. 4. It is noteworthy to mention that, in the case of the heterogeneously stabilised sample under study, all the experiments which have just been detailed were used.

\section{Results and discussion}

\subsection{Thermal ageing at $130^{\circ} \mathrm{C}$ of pure Irganox $1076 \AA$}

The $\mathrm{KBr}$ disc containing $1 \mathrm{wt} \%$ of pure Irganox $1076{ }^{\circledR}$ powder was aged at $130^{\circ} \mathrm{C}$ in air. The sampling was regularly performed throughout thermal exposure and the degradation of Irganox $1076 \circledR$ was monitored by FTIR spectroscopy in transmission mode. The FTIR spectra obtained before and after different durations at $130^{\circ} \mathrm{C}$ in air are shown in Fig. 5.
As previously reminded, Irganox 1076® can exist under different crystalline forms, each of them having a specific IR signature [29,31,38,41]. In our previous work [29], it was shown that the commercially available Irganox $1076 \AA$ powder was crystallised under the so-called Form I. For this crystalline Form I, the IR bands of the phenol $(\mathrm{O}-\mathrm{H})$ and ester functions $(\mathrm{C}=\mathrm{O})$ are observed around $3640 \mathrm{~cm}^{-1}$ and $1735 \mathrm{~cm}^{-1}$, respectively, as shown in Fig. $5 \mathbf{a}$ and Fig. 5 b. After $24 \mathrm{~h}$ of exposure at $130^{\circ} \mathrm{C}$ in air, however, several changes were observed. In the hydroxyls spectral region (i.e. between 3700 and $3550 \mathrm{~cm}^{-1}$, Fig. 5a), the IR band of phenol at $3640 \mathrm{~cm}^{-1}$ seems no longer present, but two other IR bands are now observed at $3648 \mathrm{~cm}^{-1}$ and around $3600 \mathrm{~cm}^{-1}$. Meanwhile, in the carbonyls spectral region (between 1500 and $1800 \mathrm{~cm}^{-1}$, Fig. $5 \mathbf{b})$, the IR band of the ester function of $\mathrm{AO}$ at $1735 \mathrm{~cm}^{-1}$ is still present but has significantly decreased, and a broadening band around $1719 \mathrm{~cm}^{-1}$ is observed. In addition, IR bands around $1633 \mathrm{~cm}^{-1}$ and $1600 \mathrm{~cm}^{-1}$ are also appearing. The changes observed in the hydroxyls spectral region could be due to a change in the chemical environment of the phenol functions, either due to a modification of the chemical structure of $\mathrm{AO}$ and/or a modification of intermolecular interactions involving the phenol functions of $\mathrm{AO}$.

A first possibility could be a modification of the crystalline structure of $\mathrm{AO}$ after thermal exposure at $130^{\circ} \mathrm{C}$ in air. Let us remember that the as-received Irganox $1076 \AA$ powder is crystallised 


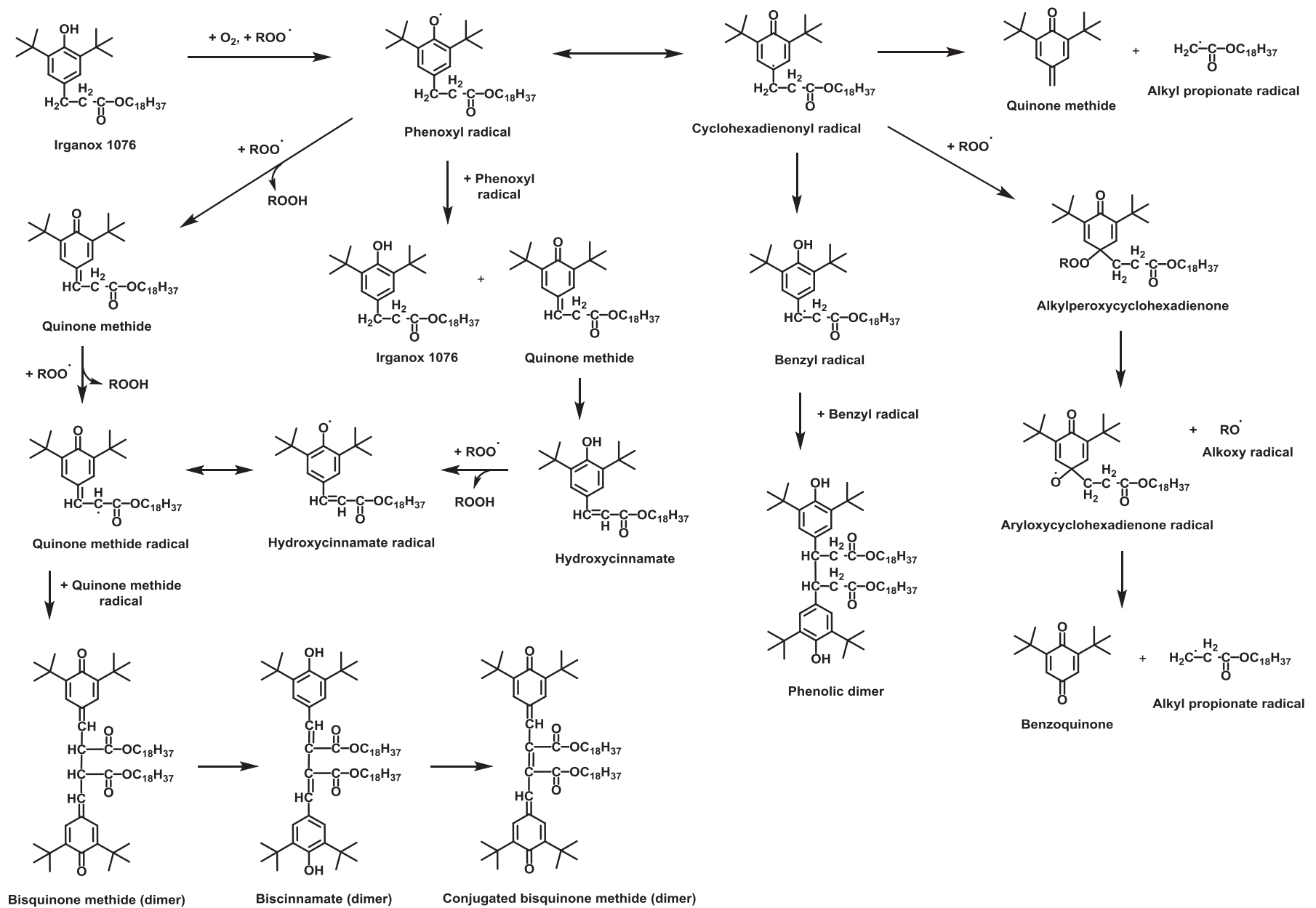

Scheme 1. Reaction pathways proposed for the thermal degradation of pure phenolic AO or polyolefins stabilised with phenolic AO [18-20,42-46].

under the so-called Form I with a melting point around $51{ }^{\circ} \mathrm{C}$. In our previous study [29], indeed, it was observed a recrystallization of this AO powder under another crystalline form after a thermal treatment above its melting point, in particular under the Form III which is characterized with a melting point around $47^{\circ} \mathrm{C}$. The new positions of the phenol and ester IR bands observed here after 24 $\mathrm{h}$ at $130^{\circ} \mathrm{C}$ could correspond to this crystalline Form III, typically characterized by IR absorptions around $3610 \mathrm{~cm}^{-1}$ and $1723 \mathrm{~cm}^{-1}$, respectively [29,31,38]. However, according to Saunier et al. [31], this crystalline Form III has another specific IR band at $1288 \mathrm{~cm}^{-1}$ (C-O stretching of the ester). But here, as shown in Fig. 5c, no IR band seems to be detected at $1288 \mathrm{~cm}^{-1}$, which does not allow us to conclude.

Another explanation could involve the change of the chemical structure of AO due to its thermal degradation. Indeed, during the thermal oxidative ageing of the pure phenolic AO, but also of polymers stabilised with phenolic AO,this latter can undergo several chemical transformations, as shown in Scheme 1 [18-20,4246]. The first radical species formed from phenolic AO during oxidative ageing are phenoxyl radicals, which can be generated by reaction of the phenol function of $\mathrm{AO}$ with various dehydrogenation agents, such as peroxyl radical $\left(\mathrm{ROO}^{\circ}\right)$ or molecular oxygen (which is a bi-radical) [20]. These phenoxyl radicals can then lead to a long list of transformation products, as shown in Scheme 1. For instance, one of the main degradation products of hindered phenols are quinone methides [18-20,42-46]. According to Pospisil [18], these species can be generated by bimolecular disproportionation, radical attack by peroxyl radicals or an intramolecular re- arrangement. In FTIR spectra, these species can typically be observed around $1630-1640 \mathrm{~cm}^{-1}(\mathrm{C}=0$ stretching) and 1590-1610 $\mathrm{cm}^{-1}$ ( $\mathrm{C}=\mathrm{C}$ stretching) [47]. The small growing IR bands observed around $1633 \mathrm{~cm}^{-1}$ and $1600 \mathrm{~cm}^{-1}$ in Fig. $5 \mathbf{b}$ could thus be attributed to quinone methides. Cinnamate species can also be detected during the oxidative ageing of pure phenolic AO or polymers stabilised with phenolic AO $[42,43,45,46]$. They can be generated by an intramolecular rearrangement of quinone methides, as shown in Scheme 1. Due to the conjugation effect in unsaturated esters, such as cinnamates, these species are typically observed in FTIR spectra at slightly lower wavenumbers than saturated esters: typically around $1710-1730 \mathrm{~cm}^{-1}$ for the $\mathrm{C}=0$ stretching of unsaturated esters, against around $1730-1750 \mathrm{~cm}^{-1}$ for the $\mathrm{C}=0$ stretching of saturated esters [16,48-51]. The IR band observed around $1719 \mathrm{~cm}^{-1}$ in Fig. $5 \mathbf{b}$ could thus correspond to cinnamate species.

Finally, as ageing in air at $130^{\circ} \mathrm{C}$ proceeds, most of the IR bands are decreasing with ageing time, at the exception of the IR bands around 1633 and $1600 \mathrm{~cm}^{-1}$, which seem rather to slightly increase, as shown in Fig. $5 \mathbf{b}$. These observation are presumably due to a combination between AO physical loss by evaporation and chemical degradation.

To summarize, several changes were observed by FTIR spectroscopy after the thermal exposure of the pure Irganox $1076 \AA$ at $130^{\circ} \mathrm{C}$ in air. Most of the changes were observed just after $24 \mathrm{~h}$ of exposure. In particular, the formation of quinone methides (IR bands around 1633 and $1600 \mathrm{~cm}^{-1}$ ) and cinnamate species (IR band at $1719 \mathrm{~cm}^{-1}$ ) are suspected to occur. Moreover, although the recrystallization of Irganox $1076 \AA$ into crystalline Form III (previously 

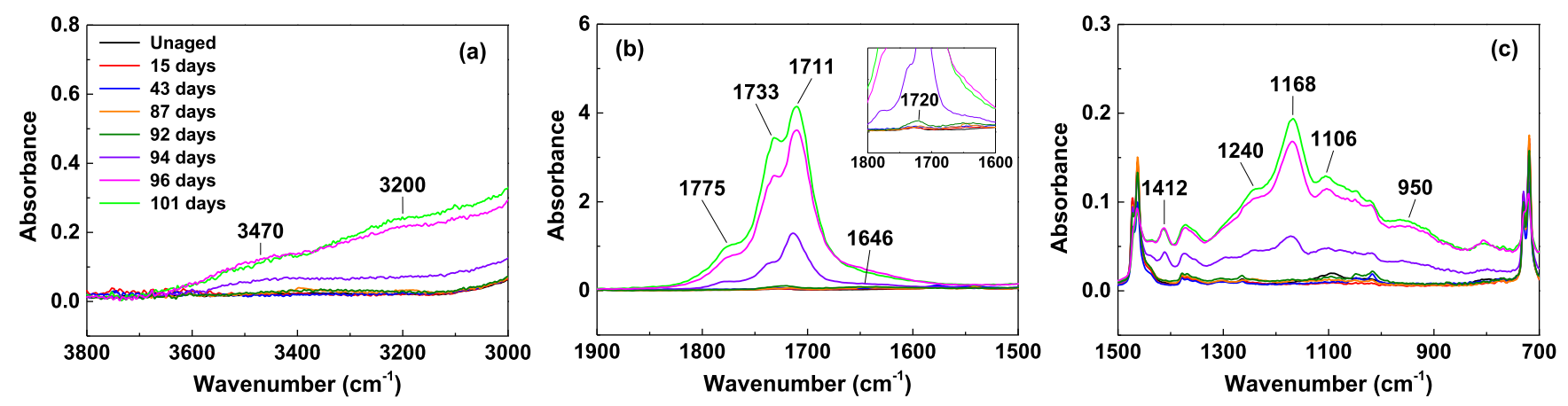

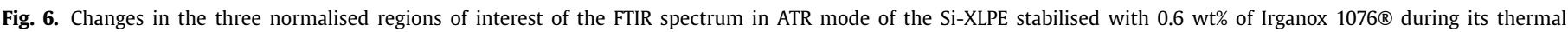
ageing at $130^{\circ} \mathrm{C}$ in air: (a) between $3800-3000 \mathrm{~cm}^{-1}$, (b) between $1900-1500 \mathrm{~cm}^{-1}$, and (c) between $1500-700 \mathrm{~cm}^{-1}$.

detected by DSC analysis) was not confirmed by FTIR spectroscopy, a modification of intermolecular interactions (such as H-bonding) involving phenol functions cannot be totally excluded, in particular to explain the formation of two new IR bands in the hydroxyls spectral region (Fig. 5a). Indeed, as new chemical species are formed during the thermal exposure of $\mathrm{AO}$, its chemical environment is modified and new intermolecular interactions can hence occur.

3.2. Physico-chemical characterization of the thermal ageing at $130^{\circ} \mathrm{C}$ of the Si-XLPE stabilised with a homogeneous distribution of Irganox $1076 \AA$

The thermal ageing under air at $130^{\circ} \mathrm{C}$ of a Si-XLPE stabilised with 0.6 wt\% of Irganox $1076 \AA$ was investigated using the general methodology detailed in Fig. 4. It should be emphasized that, in this sample, the concentration of $\mathrm{AO}$ is below the concentration threshold of $0.9 \mathrm{wt} \%$, meaning that all the AO is dissolved in the polymer matrix.

\subsubsection{Surface analysis (FTIR spectroscopy in ATR mode)}

The FTIR spectra obtained in ATR mode before and after different durations at $130^{\circ} \mathrm{C}$ in air are shown in Fig. 6. The three spectral regions of interest were normalised with the absorbance of the IR band at $1472 \mathrm{~cm}^{-1}$ assigned to the PE crystal phase [31] to better visualize the changes.

As expected, no IR band of Irganox 1076® is initially detected, and only IR bands of Si-XLPE are actually observed at the sample surface. As the ageing proceeds, no significant changes are first detected in the FTIR spectra. Then, after 92 days of exposure at $130^{\circ} \mathrm{C}$, OIT at $205^{\circ} \mathrm{C}$ becomes relatively low (about $3 \mathrm{~min}$ ), meaning that active $\mathrm{AO}$ are still present but in a very low concentration. Therefore, a small IR band, which could be due to ketones from the polymer oxidation, starts to be detected around $1720 \mathrm{~cm}^{-1}$. After 94 days of exposure at $130^{\circ} \mathrm{C}$, OIT is null and IR bands corresponding to a wide variety of oxidation products of Si-XLPE are more clearly detected. The large IR band between 3000 and 3500 $\mathrm{cm}^{-1}$ is attributed to hydroxyl functions of alcohols, hydroperoxides, and/or carboxylic acids. In the carbonyls region, the main IR bands at $1711 \mathrm{~cm}^{-1}, 1733 \mathrm{~cm}^{-1}$, and $1775 \mathrm{~cm}^{-1}$ correspond to carboxylic acids, esters, and lactones, respectively. The IR signatures of carbonyl and hydroxyl species are also observed between 1000 and $1500 \mathrm{~cm}^{-1}$, in particular around $1410 \mathrm{~cm}^{-1}$ and $1240 \mathrm{~cm}^{-1}$ where the IR bands are attributed to the C-O stretching of alcohols and/or carboxylic acids, but also around $1169 \mathrm{~cm}^{-1}$ and $1110 \mathrm{~cm}^{-1}$ where the IR bands are assigned to the $\mathrm{C}-\mathrm{O}$ stretching of carbonyls. In addition, around $950 \mathrm{~cm}^{-1}$, trans vinylene species $(C=C)$, also resulting from Si-XLPE oxidation, are detected.

\subsubsection{Morphological changes (DSC analysis)}

The DSC thermograms and the corresponding values of crystallinity ratio of the polymer (determined using Eq. 4) determined before and after different durations at $130^{\circ} \mathrm{C}$ in air are shown in Fig. 7.

As it can be observed in Fig. 7a, no melting peak of Irganox $1076 \AA$ around $50^{\circ} \mathrm{C}$ is detected, confirming that no Irganox $1076 \AA$ crystal is present in this sample. This observation is in perfect agreement with the previous results of FTIR spectroscopy in ATR mode. Moreover, a modification of the general shape of the melting peak of Si-XLPE can first be pointed out after 15 days of exposure at $130^{\circ} \mathrm{C}$. In fact, as the ageing temperature is above the melting point of Si-XLPE (about $114^{\circ} \mathrm{C}$ ), all the polymer crystals are melted during thermal exposure and thus, a total recrystallization occurs during the sample cooling at room temperature before DSC analysis. In addition, as it can be observed in Fig. $7 \mathbf{b}$, a slight decrease in the crystallinity ratio of Si-XLPE is detected during the first ageing duration, which is likely due to a post-crosslinking phenomenon of the polymer matrix. Indeed, such a phenomenon was already evidenced during the thermal ageing at $130^{\circ} \mathrm{C}$ in air of a Si-XLPE stabilised with a thiopropionate $\mathrm{AO}$ [37]. Then, as the thermal ageing proceeds, no significant modification of the crystallinity ratio of SiXLPE is observed until about 96 days. At the end of this induction period, a sudden and sharp decrease in the crystallinity ratio of SiXLPE is detected, clearly indicating the beginning of the polymer oxidation, as previously shown by FTIR spectroscopy in ATR mode.

Finally, the formation of a broad exothermic peak between 150 and $220^{\circ} \mathrm{C}$ is also observed in the DSC thermograms, in particular for the sample aged 94 days at $130^{\circ} \mathrm{C}$ in air. This exothermic peak is, in fact, due to the thermal decomposition of hydroperoxide species $(\mathrm{POOH})$, which, as shown in Scheme 1, are one of the by-products of the possible stabilisation reactions of the phenolic AO with peroxyl radicals. The concentration of $\mathrm{POOH}$ can be estimated by DSC from the area under the exothermic peak of their thermal decomposition using the following equation $[7,52,53]$ :

$[\mathrm{POOH}]=\frac{\Delta \mathrm{H}_{\mathrm{POOH}}}{\Delta \mathrm{H}_{\text {theory }}} \times \rho_{\mathrm{PE}}$

Where $\rho_{\mathbf{P E}}$ is the polymer density (here $0.918 \mathrm{~g} . \mathrm{cm}^{-3}$ ) and $\Delta \mathbf{H}_{\text {theory }}$ the theoretical enthalpy of the thermal decomposition of one mole of POOH $\left(\Delta \mathrm{H}_{\text {theory }}=-291 \mathrm{~kJ} \cdot \mathrm{mol}^{-1}\right.$ [52]).

The changes with time of exposure in the $\mathrm{POOH}$ concentration (determined by DSC) and the normalised absorbance of carbonyl species due to polymer oxidation (determined by FTIR spectroscopy in ATR mode at $1711 \mathrm{~cm}^{-1}$ ) are compared in Fig. 8. As previously said, $\mathrm{POOH}$ are detected after 94 days of exposure at $130^{\circ} \mathrm{C}$ in air with a maximum concentration of about $0.3 \mathrm{~mol} . \mathrm{L}^{-1}$. It can be observed that this duration exactly corresponds to the induction time of carbonyl species. At this time of exposure, all 

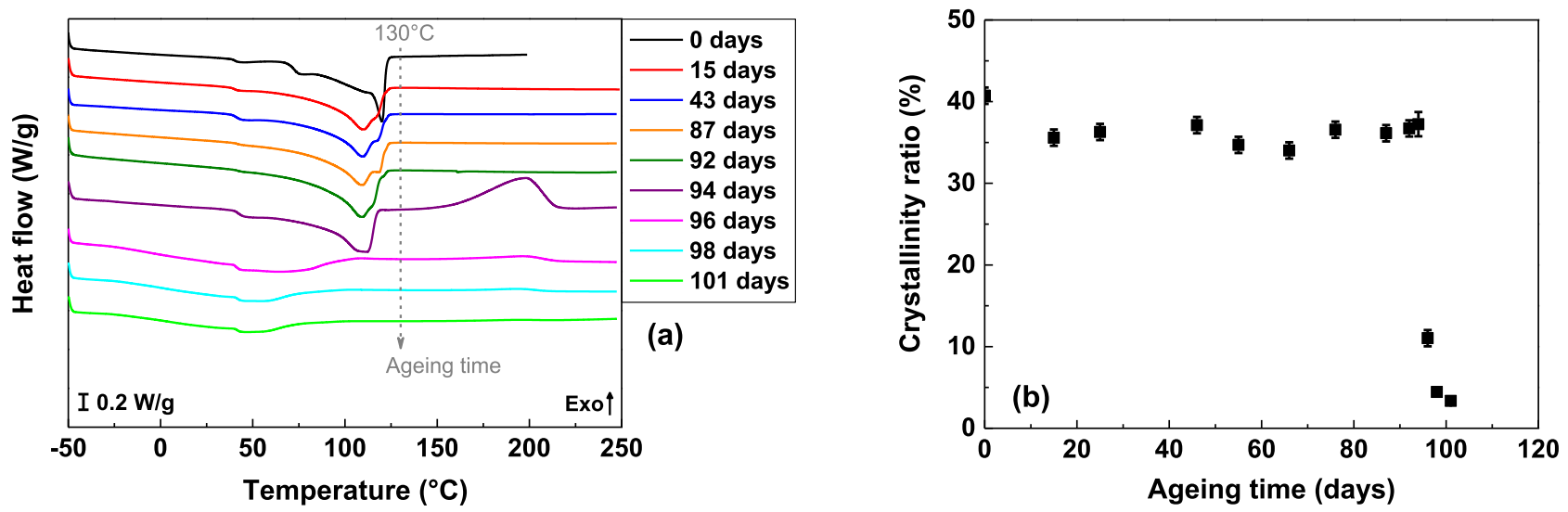

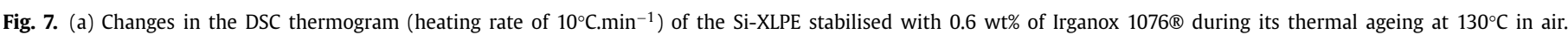
(b) Corresponding changes in the crystallinity ratio of the polymer with time of exposure.

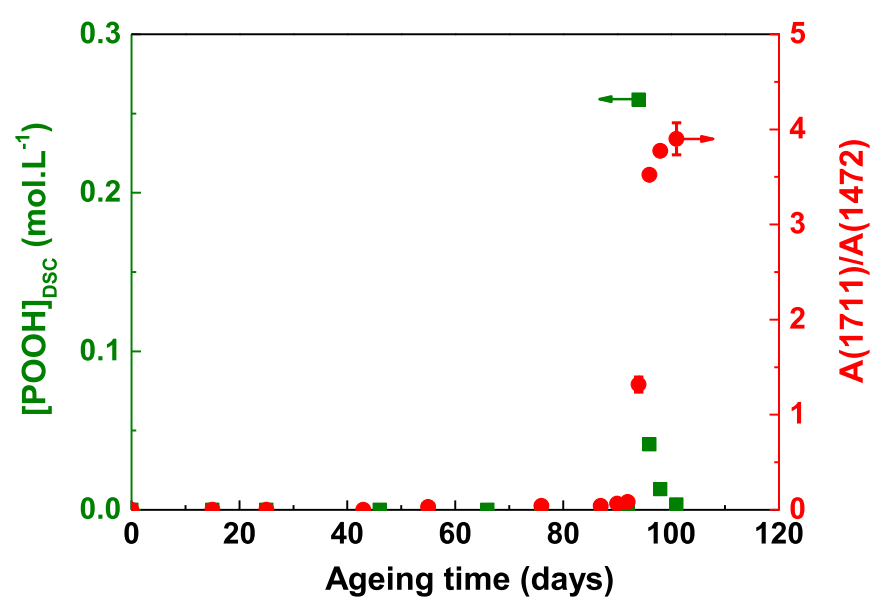

Fig. 8. Comparison of the changes in ( $\mathbf{\square})$ the hydroperoxide concentration (determined by DSC under $\mathrm{N}_{2}$ ) and $(\bullet)$ the normalised absorbance of carbonyl species (determined by FTIR spectroscopy in ATR mode at $1711 \mathrm{~cm}^{-1}$ ) during the thermal ageing at $130^{\circ} \mathrm{C}$ in air of the Si-XLPE stabilised with 0.6 wt\% of Irganox $1076 \circledast$.

the phenolic AO have been consumed by the stabilisation reactions $(\mathrm{OIT}=0)$, thus leading to an accumulation of $\mathrm{POOH}$ into the polymer matrix. It is expected that the AO consumption suddenly auto-accelerates as their concentration vanishes, because these latter have more and more difficulties in blocking the polymer oxidation. It is thus not surprising to suddenly detect $\mathrm{POOH}$ without any prior warning.

However, at $130^{\circ} \mathrm{C}$, the thermal decomposition of $\mathrm{POOH}$ (both by unimolecular and bimolecular pathways) is also very rapid. That is the reason why, as soon as they are detected, $\mathrm{POOH}$ already start to disappear from the polymer matrix, thus leading to the formation of radical species, which initiate the oxidation reaction. It should be remembered that the thermal decomposition of $\mathrm{POOH}$ is all the more rapid as their concentration is high [6,14,53]. For such a high $\mathrm{POOH}$ concentration, around $0.3 \mathrm{~mol} . \mathrm{L}^{-1}$, it is thus not surprising not to observe an additional induction period specific to the thermal oxidation of the polymer matrix without antioxidant. On the contrary, the polymer oxidation starts with a very high rate as soon as the phenolic AO have been totally consumed by the stabilisation reactions. Indeed, in Fig. 8, it can be observed an almost vertical increase of the carbonyl build-up. No doubt that, under these conditions, the embrittlement criterion of the polymer matrix will be quickly reached and the oxidation induction time would correspond to the polymer lifetime.
3.2.3. Chemical changes in the bulk

3.2.3.1. FTIR spectroscopy in transmission mode. Finally, the FTIR spectra obtained in transmission mode before and after different durations at $130^{\circ} \mathrm{C}$ in air are shown in Fig. 9. Both hydroxyls (between 3750 and $3550 \mathrm{~cm}^{-1}$ ) and carbonyls spectral regions (between 1850 and $1600 \mathrm{~cm}^{-1}$ ) were normalised with the sample thickness to better visualize the changes.

In the hydroxyls region, three main IR bands can be observed for the unaged material. The IR band at $3605 \mathrm{~cm}^{-1}$ is due to twophonon combinations of $\mathrm{CH}_{2}$ asymmetric stretching and rocking modes, i.e. to the PE matrix itself [54-56]. In addition, the IR band at $3695 \mathrm{~cm}^{-1}$ is attributed to the $\mathrm{O}-\mathrm{H}$ stretching of residual silanol functions $(\mathrm{Si}-\mathrm{OH})$ [48,57-59]. Indeed, crosslinking via the silane route first occurs by the hydrolysis of alkoxysilane functions ( $\mathrm{Si}-\mathrm{OR}$, where $\mathrm{R}$ is an alkyl function) into silanol functions, which then react with one another through a condensation reaction to form the siloxane functions ( $\mathrm{Si}-\mathrm{O}-\mathrm{Si}$ ). Finally, the third IR band at $3649 \mathrm{~cm}^{-1}$ corresponds to the phenol functions of Irganox 1076®.

In the carbonyls region, only one IR band is initially detected at $1741 \mathrm{~cm}^{-1}$, corresponding to the ester function of AO. As expected, the IR positions of the phenol and ester functions of Irganox 1076® corresponds well to those of dissolved AO (in dispersed state), as recalled in Table 1.

As already observed for the pure Irganox 1076® powder, IR bands around $1633 \mathrm{~cm}^{-1}$ and $1720 \mathrm{~cm}^{-1}$ appear during thermal ageing. As previously mentioned, these IR bands can respectively be assigned to quinone methides and hydroxycinnamates, both resulting from the chemical consumption of AO. Indeed, as the ageing proceeds, it can be observed that the IR band of the phenol functions decreases continuously. Meanwhile, in the carbonyls region, a broad IR band between 1730 and $1700 \mathrm{~cm}^{-1}$ (several types of carbonyl species) appears and increases with ageing time. This composite band is mostly visible from 43 days of exposure. Then, after 94 days of exposure, another large IR band between 3000 and $3500 \mathrm{~cm}^{-1}(\mathrm{O}-\mathrm{H}$ bonds of hydroperoxides, alcohols and/or carboxylic acids) is in turn observed, and the FTIR spectra saturate in the carbonyls region due to a significant formation of carbonyl species, i.e. high conversion ratios of the polymer oxidation reaction, as already suggested by our previous results.

Using the Beer-Lambert's law (Eq. 1), the concentrations of phenols, esters and cinnamates were estimated from FTIR results. The molar extinction coefficients of the phenol and ester functions of the $\mathrm{AO}$ dissolved in the PE matrix were already determined in a previous work [29] and are about $100 \mathrm{~L} \cdot \mathrm{mol}^{-1} \cdot \mathrm{cm}^{-1}$ and 490 L. $\mathrm{mol}^{-1} . \mathrm{cm}^{-1}$, respectively. In contrast, the molar extinction coefficients of quinones and cinnamates were selected from liter- 

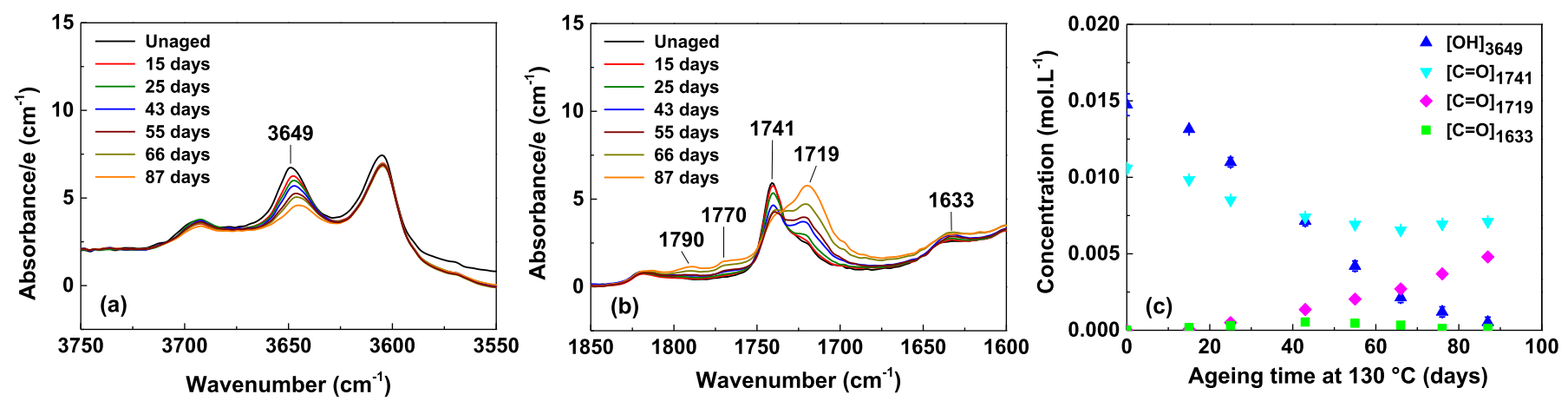

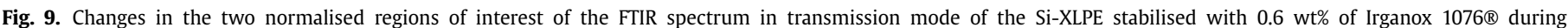

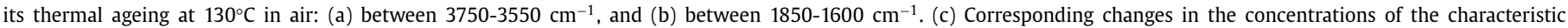
functions of AO and its degradation products with time of exposure: $(\boldsymbol{\Delta})$ phenols, $(\boldsymbol{\nabla})$ esters, $(\bullet)$ cinnamates and $(\boldsymbol{\square})$ quinones.

ature. According to Flett [51], aromatic ketones and esters have molar extinction coefficients typically ranged between 280-490 L.mol ${ }^{-1} . \mathrm{cm}^{-1}$ and 500-700 L.mol ${ }^{-1} . \mathrm{cm}^{-1}$, respectively. In a first approximation, orders of magnitude of $400 \mathrm{~L} \cdot \mathrm{mol}^{-1} . \mathrm{cm}^{-1}$ and 700 L. $\mathrm{mol}^{-1} \cdot \mathrm{cm}^{-1}$ were respectively considered in this study.

The concentrations of these four chemical functions were plotted against time of exposure in Fig. 9c. Three kinetic regimes can clearly be distinguished:

i) In the first regime (until about 43 days of exposure), the concentrations of both phenol and ester functions of AO decrease with ageing time, which can be due to its chemical consumption and/or its physical loss through evaporation. In this same regime, some quinone methides (IR band at $1633 \mathrm{~cm}^{-1}$ ) and cinnamates (IR band at $1719 \mathrm{~cm}^{-1}$ ) are also detected, indicating that the chemical consumption of $\mathrm{AO}$ is really occurring. It should be noted that the saturated ester function (initially present in Irganox 1076®) is kept in quinone methides, but has disappeared in cinnamates which, on the contrary, contain an unsaturated ester. Hence, a decrease in the saturated ester functions (IR band at $1741 \mathrm{~cm}^{-1}$ ) is either due to the AO physical loss through evaporation and/or the formation of cinnamates. At 25 days of exposure, for instance, the concentrations of formed quinone methides and cinnamates are estimated to be around $3 \times 10^{-4}$ mol. $\mathrm{L}^{-1}$ and $5 \times 10^{-4}$ mol.L ${ }^{-1}$, respectively. Meanwhile, the decreases in the concentrations of phenol and ester functions of the $\mathrm{AO}$ are estimated at approximately $4 \times 10^{-3}$ mol. $\mathrm{L}^{-1}$ and $2 \times 10^{-3} \mathrm{~mol} . \mathrm{L}^{-1}$, respectively. These results hence suggest that, in this first regime, the evaporation of AO predominates largely over its chemical consumption since its characteristic functions (phenol and ester) disappear one order of magnitude faster than the formation of its degradation products (quinone methides and cinnamates). In fact, let us remind that in stabilised polymers, the chemical consumption of phenolic $\mathrm{AO}$ generally is due to the reaction of $\mathrm{AO}$ with peroxyl radicals $\left(\mathrm{POO}^{\circ}\right)$ resulting from the polymer oxidation. However, in stabilised polymers, the initial concentration of $\mathrm{POOH}$ (and thus, of peroxyl radicals) is generally very low, which could explain the few chemical consumption of AO observed in this first regime. Moreover, as quinone methides and cinnamates were also detected during the thermal ageing at $130^{\circ} \mathrm{C}$ in air of the pure $\mathrm{AO}$ powder, the chemical consumption of $\mathrm{AO}$, from the direct reaction of AO with molecular oxygen (which is a bi-radical), can also not be totally excluded; although such a reaction is generally considered negligible in the case of hydrocarbon poly- mers exposed to such conditions (i.e. typically at $\mathrm{T}<200^{\circ} \mathrm{C}$ and under low $\mathrm{O}_{2}$ partial pressures) $[26,42,60]$.

ii) In the second regime (between 43 and 66 days of exposure), the concentration of esters (IR band at $1741 \mathrm{~cm}^{-1}$ ) seems to remain relatively constant around $7 \times 10^{-3}$ mol. $\mathrm{L}^{-1}$ although the concentration of phenols continues to decrease with ageing time. In the same time, the concentration of quinone methides decreases, while the concentration of cinnamates (IR band at $1719 \mathrm{~cm}^{-1}$ ) increases more significantly. Let us recall that, according to literature, and reminded in Scheme 1, cinnamates are formed by an intramolecular rearrangement of quinone methides, which could explain the opposite evolutions in the concentrations of these two chemical species. In addition, it is also noteworthy that, according to literature [61], alkylperoxycyclohexadienone species would also be formed in high yield from the reaction between phenolic AO and peroxyl radicals. The carbonyl moiety of these species can, according to literature, typically be detected around $1695-1712 \mathrm{~cm}^{-1}$ [61]. The apparent increase of cinnamates concentration (IR band at $1719 \mathrm{~cm}^{-1}$ ) could, hence, also be due to the formation of alkylperoxycyclohexadienones, which absorb in almost the same spectral range. Indeed, it can be observed that the corresponding carbonyl IR massif is relatively broad and thus, might contain the contributions of several species. In addition, let us note that saturated ester functions are present in alkylperoxycyclohexadienones, but not in cinnamates. Thus, the formation of alkylperoxycyclohexadienones does not involve the depletion of saturated ester functions (IR band at $1741 \mathrm{~cm}^{-1}$ ), unlike the formation of cinnamates. As the increase in the IR band at $1719 \mathrm{~cm}^{-1}$ is accompanied with the depletion of phenol functions but no apparent change in the concentration of saturated esters, the formation of alkylperoxycyclohexadienones is also suspected to occur. Moreover, as reminded in Fig. 1 and Scheme 1, the formation of alkylperoxycyclohexadienones requires the presence of peroxyl radicals, which are formed from the polymer oxidation. According to literature [26,62], the chemical consumption of phenolic AO by peroxyl radicals should be observed after an induction period, as the initial concentration of $\mathrm{POOH}$ (and thus, peroxyl radicals $\mathrm{POO}^{\circ}$ ) is generally very low, if not near zero. Finally, it should be mentioned that, in the long term, the IR bands of saturated esters (at $1741 \mathrm{~cm}^{-1}$ ) and cinnamates (at $1719 \mathrm{~cm}^{-1}$ ) should also be impacted by the formation of some oxidation products from the polymer matrix, such as aldehydes and ketones, which respectively absorb around $1730-1740 \mathrm{~cm}^{-1}$ and $1718-1720 \mathrm{~cm}^{-1}$ $[37,63,64]$. 

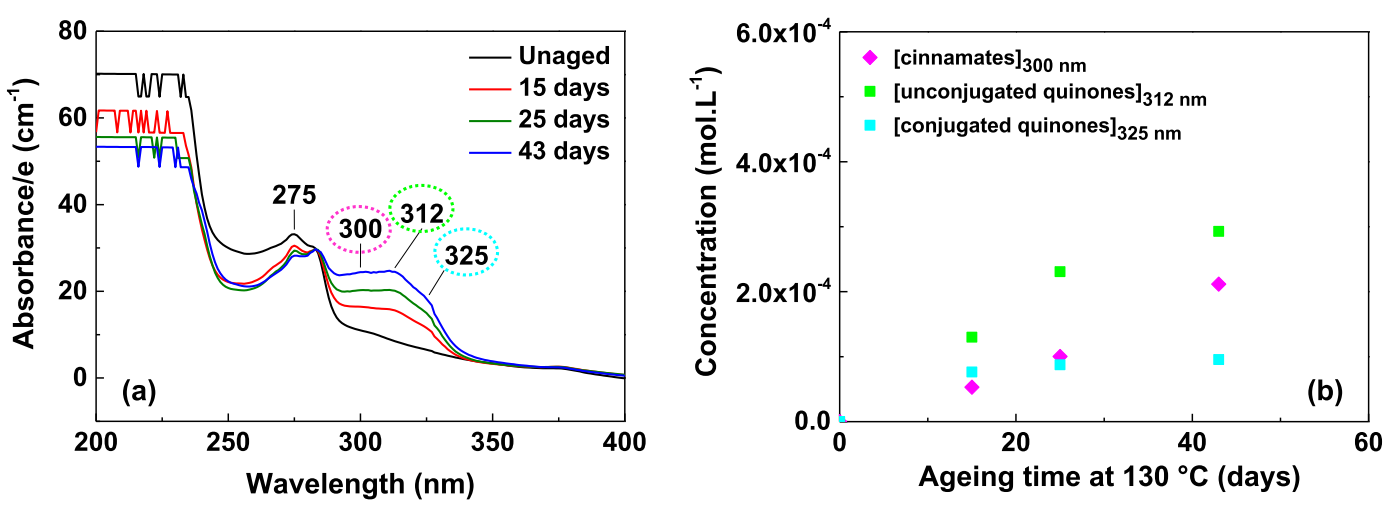

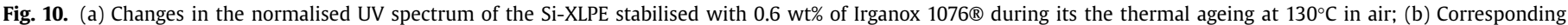
changes in the concentrations of $(\bullet)$ cinnamates, $(\boldsymbol{\square})$ conjugated quinones and $(\mathbf{\square})$ unconjugated quinones with time of exposure.

iii) In the last regime (i.e. beyond 66 days of exposure), the IR bands around $1770-1790 \mathrm{~cm}^{-1}$ slightly increase, presumably due to the formation of lactones from the polymer oxidation. A similar behaviour was observed in a previous work on the thermal ageing of a Si-XLPE stabilised with a thiodipropionate AO [37].

3.2.3.2. UV spectroscopy in transmission mode. As shown previously, quinones can be detected around $1633 \mathrm{~cm}^{-1}$ by FTIR spectroscopy. However, as shown in Fig. $5 \mathbf{b}$ and Fig. 9b, their absorbance is generally very low. In literature, UV spectroscopy is hence more often used to detect them as their molar extinction coefficient in UV is much higher. In fact, Klemchuk and Horng [36] found molar extinction coefficients of about 35000 (at $314 \mathrm{~nm}$ ) and $45000 \mathrm{~L} \cdot \mathrm{mol}^{-1} \cdot \mathrm{cm}^{-1}$ (at $322 \mathrm{~nm}$ ) for unconjugated and conjugated bisquinonemethides, respectively.

The UV spectra obtained before and after different durations at $130^{\circ} \mathrm{C}$ in air are shown in Fig. 10 a. These spectra were also normalised with the film thickness (e) to better visualize the changes. In UV spectroscopy, in addition to quinone methides, the aromatic phenols and hydroxycinnamates can also be detected around 275 $\mathrm{nm}$ and $300 \mathrm{~nm}$ [36], respectively.

As for FTIR spectroscopy, the Beer-Lambert's law (Eq. 1) was used to quantify the chemical species detected by UV spectroscopy. In particular, the concentration of quinone methides and cinnamates were estimated using the following molar extinction coefficients from literature: $35000 \mathrm{~L} \cdot \mathrm{mol}^{-1} \cdot \mathrm{cm}^{-1}$ for conjugated quinones (UV band at $325 \mathrm{~nm}$ ), $45000 \mathrm{~L} \cdot \mathrm{mol}^{-1} \cdot \mathrm{cm}^{-1}$ for unconjugated quinones (UV band at $312 \mathrm{~nm}$ ) [36], and 35000 L. $\mathrm{mol}^{-1} . \mathrm{cm}^{-1}$ for hydroxycinnamates (UV band at $300 \mathrm{~nm}$ ) [36]. The calculated concentrations were then plotted against time of exposure in Fig. 10b.

The results obtained by UV spectroscopy suggest that quinone methides are the main degradation products of $\mathrm{AO}$, with a total concentration of about $3 \times 10^{-4}$ mol. $\mathrm{L}^{-1}$ after 25 days of exposure at $130^{\circ} \mathrm{C}$, while the concentration of cinnamates is about $1 \times 10^{-4}$ mol. $\mathrm{L}^{-1}$. This is the same concentration of quinones previously determined by FTIR spectroscopy. In contrast, the concentration of cinnamates is about five times lower than previously determined by FTIR spectroscopy. This concentration difference might be due to the additional contribution of carbonyl species due to polymer oxidation in FTIR spectroscopy, as previously mentioned. However, it should be pointed out that this difference is totally negligible at low conversion ratios, for instance after 15 days of exposure at $130^{\circ} \mathrm{C}$. In this case, indeed, the concentrations of quinones and cinnamates estimated by FTIR and UV spectroscopies are of the same order of magnitude, thus giving a good confidence in the values of the molar extinction coefficients chosen for this study.
Unfortunately, for heterogeneously stabilised samples (i.e. with a concentration of Irganox $1076 \AA$ higher than $0.9 \mathrm{wt} \%)$, UV spectroscopy could not be used to quantify the $\mathrm{AO}$ and its degradation products due to the saturation of the corresponding UV absorption bands. Thus, for these samples, only FTIR spectroscopy was used.

\subsection{Physico-chemical characterization of the thermal ageing of the} Si-XLPE stabilised with an excess of Irganox 1076®

The thermal ageing of a Si-XLPE stabilised with $2.1 \mathrm{wt} \%$ of Irganox $1076 \circledast$ was investigated in air at three different temperatures: $87^{\circ} \mathrm{C}, 110^{\circ} \mathrm{C}$, and $130^{\circ} \mathrm{C}$, using the same general methodology detailed in Fig. 4.

\subsubsection{Surface analysis (FTIR spectroscopy in ATR mode vs. Optical microscopy)}

The FTIR spectra in ATR mode obtained before and after different durations at $87^{\circ} \mathrm{C}, 110^{\circ} \mathrm{C}$, and $130^{\circ} \mathrm{C}$ in air are shown in Fig. 11 , Fig. 12, and Fig. 13, respectively. As for the homogeneously stabilised sample, a special attention was paid to the three spectral regions of interest normalised with the IR band at $1472 \mathrm{~cm}^{-1}$.

AO crystals are initially detected on the film surface. Indeed, the initial FTIR spectrum contains IR bands at 3639 and $1733 \mathrm{~cm}^{-1}$ corresponding to the phenol and ester functions of $\mathrm{AO}$ under the crystalline Form I, respectively. As a reminder, the material under study was stabilised by an initial concentration of Irganox 1076® above its solubility threshold (about 0.9 wt\%) in PE-based materials [29,33]. These AO in excess exuded and recrystallized at the sample surface during the processing operation [33].

As the thermal ageing proceeds, the IR bands of AO crystals under the Form I decrease for the three exposure temperatures under investigation, suggesting a decrease of the amount of AO crystals present at the sample surface. In addition, in the case of thermal ageing at $130^{\circ} \mathrm{C}$ (Fig. 13), the formation of IR bands at 3612 $\mathrm{cm}^{-1}$ and $1723 \mathrm{~cm}^{-1}$ is observed after 71 days of exposure. These IR bands are characteristic of AO under the crystalline Form III, as recalled in Table 1. Only in this case, an additional IR band is detected at $1288 \mathrm{~cm}^{-1}$, which is not present, neither for the unaged, nor for all other aged samples. According to Saunier et al. [31], this IR band at $1288 \mathrm{~cm}^{-1}$ is specific to the crystalline Forms II and III (C-O stretching of the ester) as it is not observed for the crystalline Form I. In order to confirm the presence of this new crystalline form of AO, the sample surface was examined by optical microscopy before and after 71 days of exposure at $130^{\circ} \mathrm{C}$. Indeed, it was shown in literature that, depending on the crystalline form involved, Irganox $1076 \AA$ crystals can have specific shapes and, in particular, the crystalline Form III of Irganox 1076® was observed as needle-shaped crystals $[29,31]$. On Fig. 14, it can be observed 

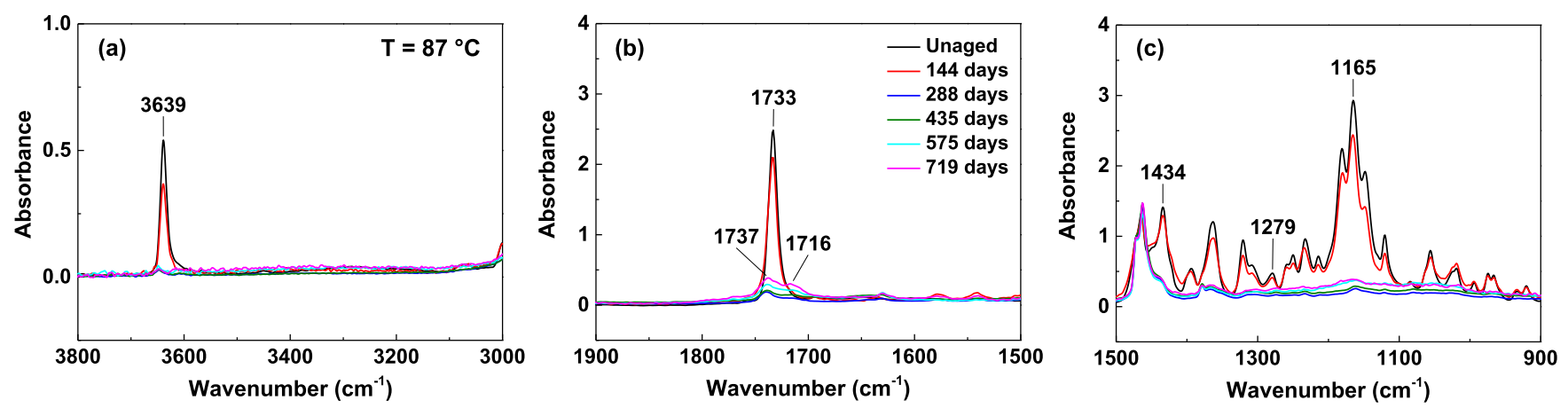

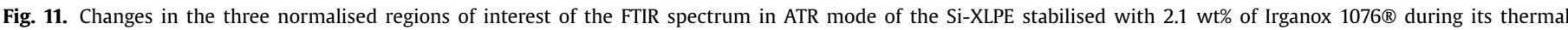
ageing at $87^{\circ} \mathrm{C}$ in air: (a) between $3800-3000 \mathrm{~cm}^{-1}$, (b) between $1900-1500 \mathrm{~cm}^{-1}$, and (c) between $1500-900 \mathrm{~cm}^{-1}$.
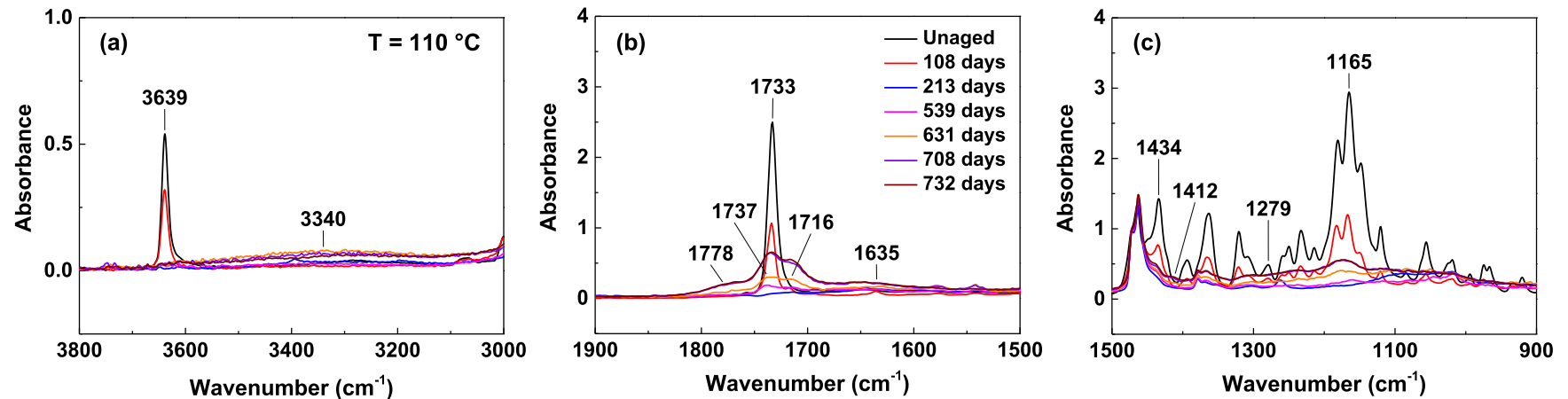

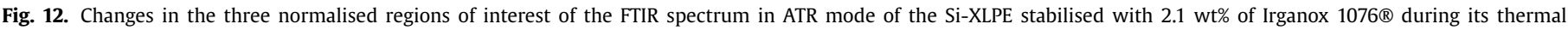
ageing at $110^{\circ} \mathrm{C}$ in air: (a) between $3800-3000 \mathrm{~cm}^{-1}$, (b) between $1900-1500 \mathrm{~cm}^{-1}$, and (c) between $1500-900 \mathrm{~cm}^{-1}$.
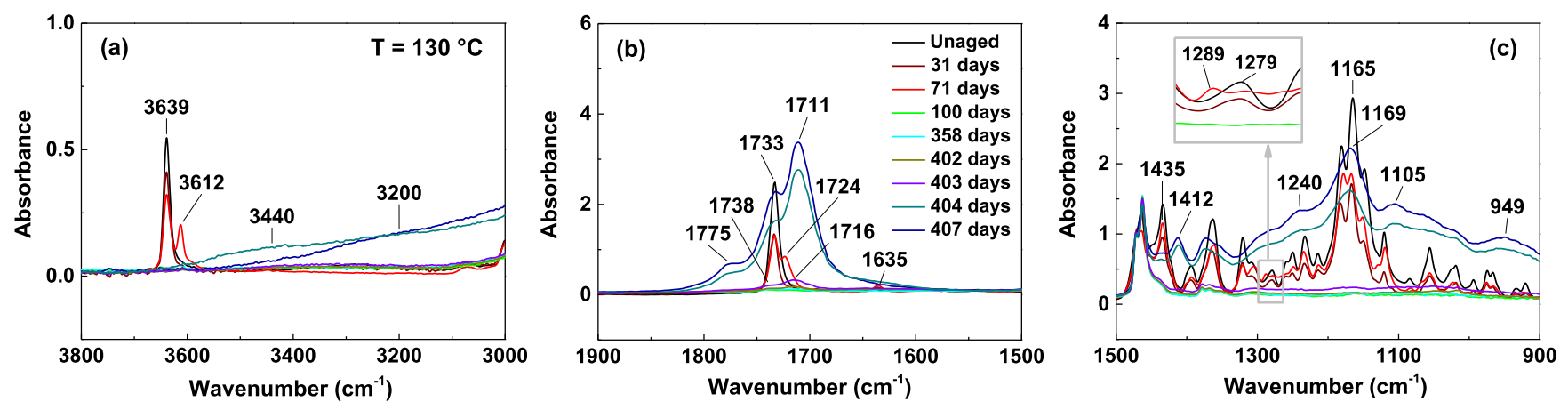

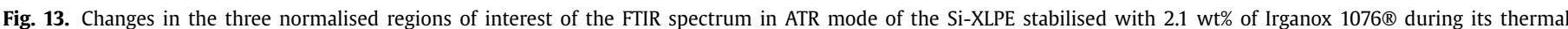
ageing at $130^{\circ} \mathrm{C}$ in air: (a) between $3800-3000 \mathrm{~cm}^{-1}$, (b) between $1900-1500 \mathrm{~cm}^{-1}$, and (c) between $1500-900 \mathrm{~cm}^{-1}$.
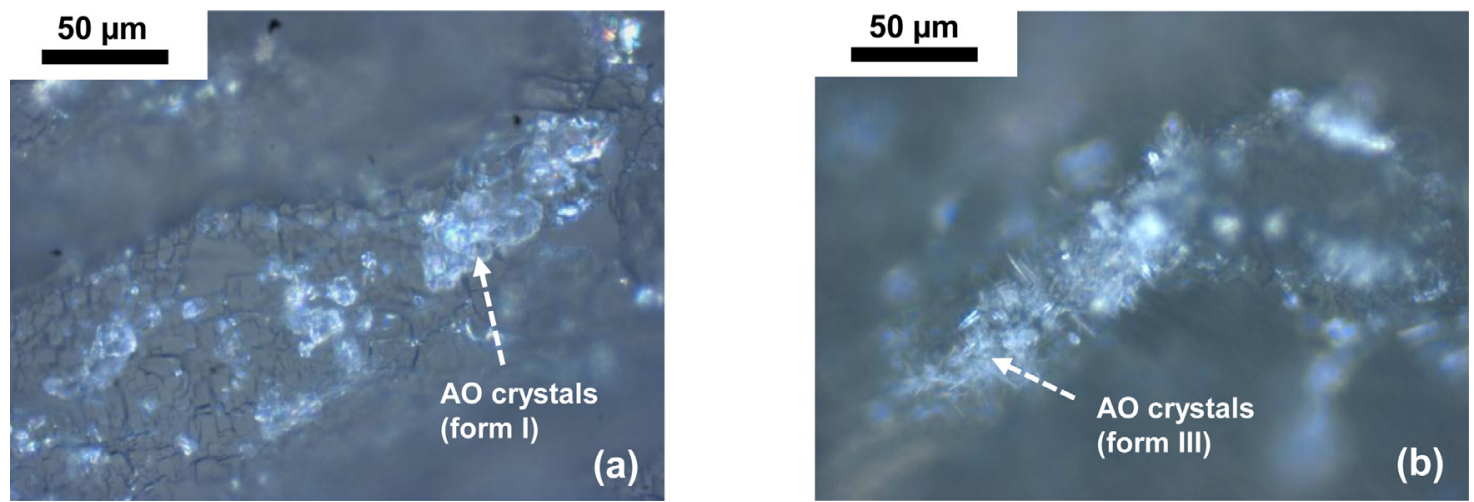

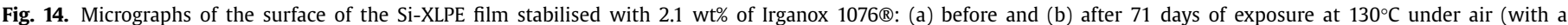
magnification of $\times 500$ ). 
that before thermal ageing, AO crystals of various sizes (from few microns to a dozen of microns) were present at the sample surface, while after 71 days of exposure at $130^{\circ} \mathrm{C}$, needle-shaped crystals are now covering the sample surface. It can be thus concluded that both FTIR spectroscopy in ATR mode and optical microscopy confirm the polymorphism of Irganox 1076® after 71 days of exposure at $130^{\circ} \mathrm{C}$ in air.

For the three exposure temperatures under investigation and, in particular, for thermal ageing at $130^{\circ} \mathrm{C}$, the appearance of an IR band around $1630-1635 \mathrm{~cm}^{-1}$ was also noticed during the early periods of exposure. It should be recalled that this IR band was already observed during the thermal ageing at $130^{\circ} \mathrm{C}$ in air of both of the pure AO powder and the homogeneously stabilised Si-XLPE film. It is assigned to quinone methides resulting from the reaction of the phenol function of $\mathrm{AO}$ with peroxyl radicals and/or molecular oxygen. These observations hence suggest that, while the amount of AO crystals decreases with time of exposure on the sample surface, due to a further dissolution of AO into the polymer matrix favoured by the sample exposure to higher temperatures (the melting point of $\mathrm{AO}$ crystals is about $50^{\circ} \mathrm{C}$ ) and/or its evaporation, a non-negligible part of the $\mathrm{AO}$ is also chemically consumed. Unfortunately, at this stage of the investigations, it is not possible to know in which physical state (i.e. dissolved or crystallised) are the AO the most prone to chemical consumption. This is surely a difficult problem to solve because it cannot be excluded that a part of the degradation products (e.g. quinone methides and cinnamates) formed in the AO crystals dissolves into the polymer matrix during thermal ageing, since these latter are less polar than the initial phenolic AO.

Then, as the thermal ageing proceeds, no IR band is detected for AO at the sample surface, in contrast, a slight growth in the IR bands in the carbonyls spectral range (around $1737 \mathrm{~cm}^{-1}$ and 1716 $\mathrm{cm}^{-1}$ ) is noticed. These latter are typically attributed to aldehydes and ketones from PE oxidation. The increase in their absorbance with time of exposure is clearly a sign of the onset of polymer oxidation at the sample surface, as these IR bands were also observed during the thermal ageing of the pure Si-XLPE. Indeed, as for a linear PE [65,66], the thermal oxidation of Si-XLPE leads to the formation of a wide variety of carbonyl species such as: carboxylic acids and saturated ketones (typically between 1700 and $1720 \mathrm{~cm}^{-1}$ ), aldehydes and esters (between 1730 and $1740 \mathrm{~cm}^{-1}$ ), and $\gamma$-lactones (around 1770-1790 $\mathrm{cm}^{-1}$ ) [48,65-67].

For thermal ageing at $130^{\circ} \mathrm{C}$ in air, in particular, these IR bands first slowly increase up to 404 days of exposure for which, as previously observed for the homogenously stabilised sample, oxidation accelerates suddenly. In contrast, for the other two temperatures of exposure $\left(87\right.$ and $\left.110^{\circ} \mathrm{C}\right)$, although some oxidation products of polymer are detected by FTIR spectroscopy in ATR mode, their absorbance remain quite low. It should be noted that the OIT values measured at $205^{\circ} \mathrm{C}$ for most samples aged at $87^{\circ} \mathrm{C}$ and $110^{\circ} \mathrm{C}$ are still non-null: about $100 \mathrm{~min}$ after 720 days of exposure at $87^{\circ} \mathrm{C}$ and about $20 \mathrm{~min}$ after 740 days at $110^{\circ} \mathrm{C}$. They correspond to AO concentrations of about $3 \times 10^{-2}$ mol. $\mathrm{L}^{-1}$ and $5 \times 10^{-3} \mathrm{mol.L}-1$, respectively. These concentrations were estimated using Eq. 2 and the calibration curve obtained for OIT at $205^{\circ} \mathrm{C}$ in our previous work [33].

\subsubsection{Morphological changes (DSC analysis)}

Fig. 15 shows the DSC thermograms (under $\mathrm{N}_{2}$ ) obtained during the thermal ageing at $87^{\circ} \mathrm{C}, 110^{\circ} \mathrm{C}$, and $130^{\circ} \mathrm{C}$ in air of the heterogeneously stabilised Si-XLPE film.

A modification of the general shape of the melting peak of Si-XLPE can be noticed in the early periods of exposure for the three temperatures under investigation. The same behaviour was observed during the thermal ageing of a Si-XLPE stabilised with a thiopropionate AO [37], and for the Si-XLPE film stabilised with 0.6 wt\% of Irganox $1076{ }^{\circledR}$ aged at $130^{\circ} \mathrm{C}$. These modifications are due to the partial or total melting of polymer crystals during thermal ageing. When the temperature of exposure is located within the melting range of $\mathrm{Si}-\mathrm{XLPE}$ (i.e. at $87^{\circ} \mathrm{C}$ and $110^{\circ} \mathrm{C}$ ), almost all the smallest crystals having a melting point lower than the temperature of exposure are transformed into larger crystals which are stable at the temperature of exposure, presumably by coalescence $[68,69]$. As a consequence, the lower part of the melting peak disappears, the melting peak becomes narrower and can be shifted towards higher temperatures (in particular at $110^{\circ} \mathrm{C}$ ). Under these conditions, it is not surprising that almost no recrystallization is observed during the sample cooling to room temperature before DSC analysis, except perhaps at $110^{\circ} \mathrm{C}$ where a small secondary melting peak can be seen around $90^{\circ} \mathrm{C}$ on the DSC thermograms.

When the temperature of exposure is higher than the melting range of $\mathrm{Si}-\mathrm{XLPE}$ (i.e. at $130^{\circ} \mathrm{C}$ ), in contrast, all the polymer crystals are melted during the thermal ageing and a total recrystallization occurs during the sample cooling at room temperature before the DSC analysis. It should be pointed out that the SiXLPE was crosslinked in its solid state (at $65^{\circ} \mathrm{C}$ ). Therefore, this crosslinked polymer is initially characterized by the same crystalline morphology as the starting linear low density polyethylene (Si-g-LLDPE). However, in molten state, its macromolecular chains are now crosslinked and thus, are characterized by a reduced molecular mobility which hinders the recrystallization of the largest crystals. It is thus not surprising to observe a widening and a shift of the melting peak towards the lower temperatures after recrystallization. These changes in crystalline morphology seem to be accelerated with the polymer oxidation, in particular from 404 days of exposure in air at $130^{\circ} \mathrm{C}$.

As the thermal ageing proceeds, no additional modification is observed on the DSC thermograms for the two lowest temperatures, which is consistent with the previous results. Indeed, it should be remembered that, at 87 and $110^{\circ} \mathrm{C}$, OIT never becomes null and very few polymer oxidation products are detected by FTIR spectroscopy in ATR mode. In contrast, at $130^{\circ} \mathrm{C}$, as already observed for the homogeneously stabilised Si-XLPE (Fig. 7), a broad exothermic peak starts to appear on the DSC thermogram between 130 and $220^{\circ} \mathrm{C}$ after 402 days of exposure, due to the thermal decomposition of $\mathrm{POOH}$ species. The concentration of $\mathrm{POOH}$ accumulated in the polymer matrix was estimated using Eq. 5 and plotted against time of exposure in Fig. 16. As for the homogeneously stabilised sample, the normalised absorbance of carbonyl species due to polymer oxidation (determined by FTIR spectroscopy in ATR mode at $1711 \mathrm{~cm}^{-1}$ ) has also been plotted in the same graph.

As for the homogeneously stabilised sample, as soon as the phenolic AO are completely depleted (OIT $=0)$, the hydroperoxides are suddenly detected by DSC with a maximum concentration of about $0.1 \mathrm{~mol} . \mathrm{L}^{-1}$. These latter immediately initiate the thermal oxidation of the polymer matrix with a very high rate. However, as expected, the induction time of carbonyl species is much longer for the heterogeneously than the homogeneously stabilised sample: 404 days against 94 days of exposure at $130^{\circ} \mathrm{C}$ in air.

Now, if looking at the crystallinity ratio of Si-XLPE determined with Eq. 4, no significant change is observed during the thermal ageing at 87 and $110^{\circ} \mathrm{C}$ in air, as shown in Fig. 17. Indeed, there is still no significant sign of polymer oxidation, although some IR bands of oxidation products were detected by FTIR spectroscopy in ATR mode (Fig. 11 and Fig. 12). At $130^{\circ} \mathrm{C}$ in air, in contrast, an initial slight decrease in the crystallinity ratio (typically from 41 $\pm 1 \%$ up to $37 \pm 1 \%$ after 30 days of exposure) is observed presumably due to the polymer post-crosslinking in molten state. This assumption was successfully checked by swelling test in refluxing p-xylene (typically from $71 \pm 1 \%$ up to $76 \pm 1 \%$ after 71 days of exposure). After 404 days of exposure, a sudden catastrophic decrease in the crystallinity ratio is detected due to polymer ox- 

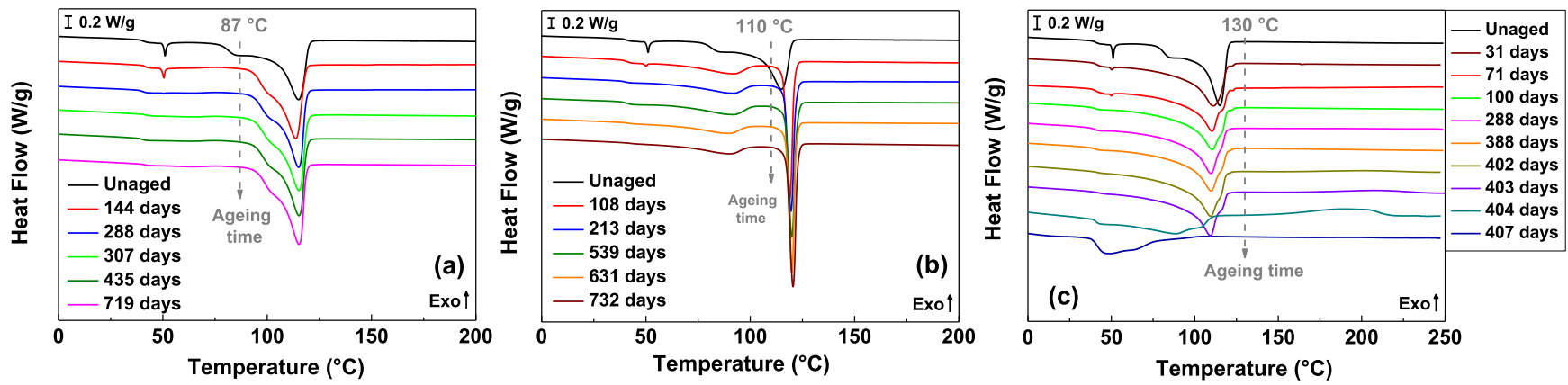

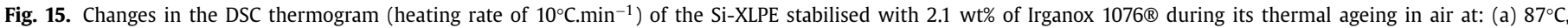
(b) $110^{\circ} \mathrm{C}$, and (c) $130^{\circ} \mathrm{C}$.

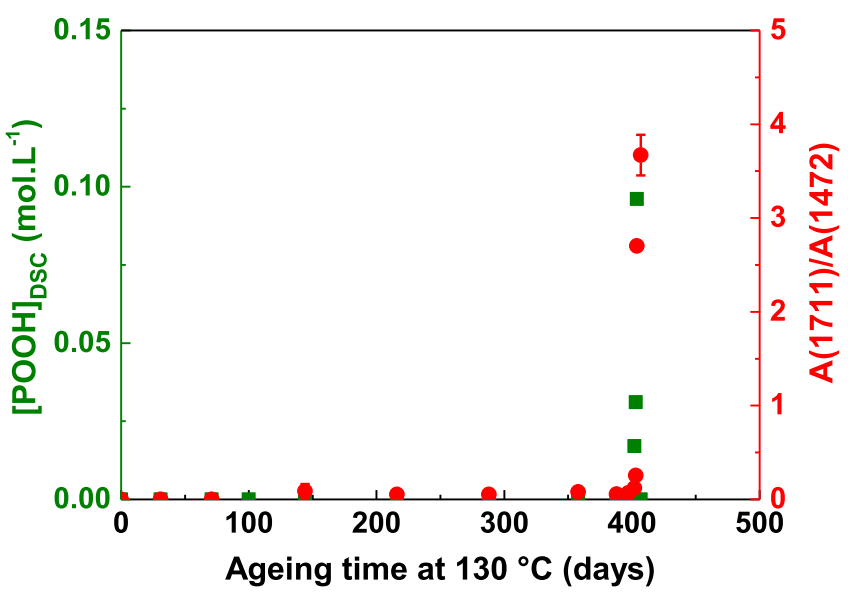

Fig. 16. Comparison of the changes in $(\boldsymbol{\square})$ the hydroperoxide concentration (obtained by DSC under $\mathrm{N}_{2}$ ) and $(\bullet)$ the normalised absorbance of carbonyl species (determined by FTIR spectroscopy ATR mode at $1711 \mathrm{~cm}^{-1}$ ) during the thermal ageing at $130^{\circ} \mathrm{C}$ in air of the Si-XLPE stabilised with $2.1 \mathrm{wt} \%$ of Irganox $1076 \circledast$.

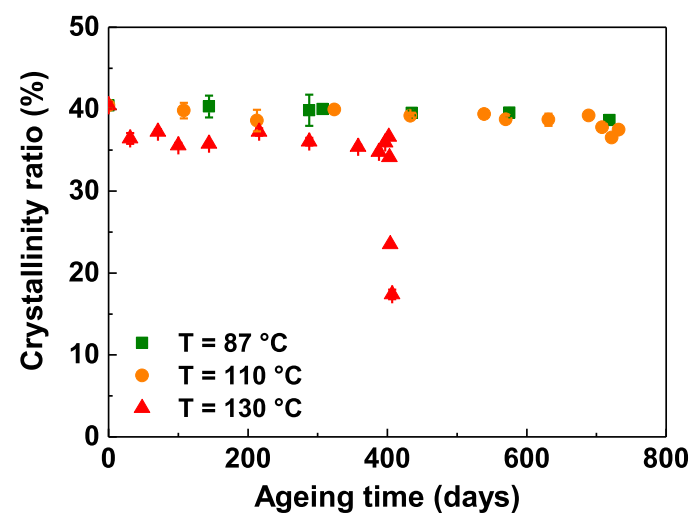

Fig. 17. Changes in the crystallinity ratio of the Si-XLPE stabilised with 2.1 wt\% of Irganox $1076 \circledR$ during its thermal ageing in air at $(\boldsymbol{\square}) 87^{\circ} \mathrm{C},(\bullet) 110^{\circ} \mathrm{C}$, and $(\boldsymbol{\Delta}) 130^{\circ} \mathrm{C}$.

idation. Indeed, this duration exactly corresponds to the induction time of carbonyl species detected by FTIR spectroscopy in ATR mode (Fig. 16). It should be remembered that the same behaviour was observed for the homogeneously stabilised Si-XLPE with 0.6 wt\% of AO (Fig. 7) and for the pure Si-XLPE both aged at $130^{\circ} \mathrm{C}$ in air.

Moreover, the DSC thermograms, determined in the first periods of exposure at the three temperatures under investigation in Fig. 15 , have been zoomed between 30 and $70^{\circ} \mathrm{C}$ in Fig. 18. In this temperature range, an endothermic peak is clearly detected at $51^{\circ} \mathrm{C}$ on the initial DSC thermogram. It should be remembered that this latter is assigned to the melting of Irganox $1076 \AA$ crystals under the Form I (Table 2). For the three temperatures of exposure, this peak disappear with ageing time. There is thus a continuous decrease in the concentration of AO crystals during thermal ageing, as already shown by FTIR spectroscopy in ATR mode. When AO crystals are no longer detected at the sample surface by FTIR spectroscopy in ATR mode (Fig. 11, Fig. 12, Fig. 13), there is no longer melting peak of AO crystals on the DSC thermograms. This result is not surprising because, in our previous study [33], it was shown that AO crystals are only present at the sample surface.

Table 3 compiles the concentrations of AO crystals estimated by DSC (using Eq. 3) during the thermal ageing in air at $87^{\circ} \mathrm{C}, 110^{\circ} \mathrm{C}$, and $130^{\circ} \mathrm{C}$, for the heterogeneously stabilised Si-XLPE film.

Finally, after 71 days of exposure at $130^{\circ} \mathrm{C}$, a second endothermic peak is detected by DSC at a slightly lower temperature $\left(47^{\circ} \mathrm{C}\right)$ than the melting peak of the initial crystalline Form I of $\mathrm{AO}\left(51^{\circ} \mathrm{C}\right)$. According to Table 2, this new peak is assigned to the melting of Irganox $1076 \AA$ crystals under the Form III. This result is also in perfect agreement with the previous FTIR analyses in ATR mode and the pervious examinations by optical microscopy which both showed the presence of Irganox $1076 \AA$ crystals under the Form III at the sample surface for the same thermal exposure conditions.

\subsubsection{Chemical changes in the bulk (FTIR spectroscopy in transmission mode)}

Finally, the FTIR spectra obtained in transmission mode before and after different durations in air at the three different temperatures under investigation are shown in Fig. 19. Both hydroxyls (between 3750 and $3850 \mathrm{~cm}^{-1}$ ) and carbonyls spectral regions (between 1850 and $1600 \mathrm{~cm}^{-1}$ ) were normalised with the sample thickness to better visualize the changes.

In the hydroxyls region, three main IR bands were observed for the unaged material. As a reminder, the IR band at $3605 \mathrm{~cm}^{-1}$ is due to the PE matrix itself, while the IR band at $3695 \mathrm{~cm}^{-1}$ is due to the O-H stretching from residual silanol functions. The third IR band centred at $3642 \mathrm{~cm}^{-1}$ is attributed to the phenol function of Irganox $1076 \AA$. In particular, as reminded in Table 1 , this latter corresponds to the crystalline Form I of Irganox 1076®.

During the first periods of exposure, the same behaviour is observed for the three temperatures under investigation. At first, it can be noticed that the IR band at $3695 \mathrm{~cm}^{-1}$ (Si-OH) decreases due to the post-crosslinking of the polymer matrix via the condensation of residual $\mathrm{Si}-\mathrm{OH}$ functions. Then, as also previously observed for the thermal ageing of the pure AO powder and the homogeneously stabilised Si-XLPE in air at $130^{\circ} \mathrm{C}$, two new IR bands appear between $1650-1600 \mathrm{~cm}^{-1}$ and around $1720 \mathrm{~cm}^{-1}$ on the FTIR spectrum. As a reminder, these two IR bands were respectively attributed to quinone methides and hydroxycinnamates, both 

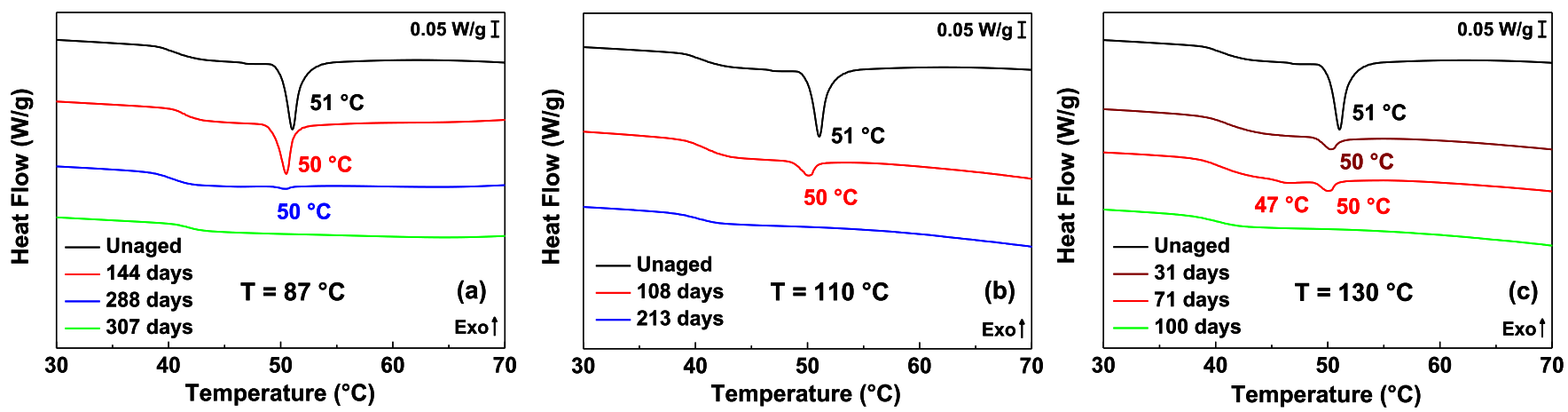

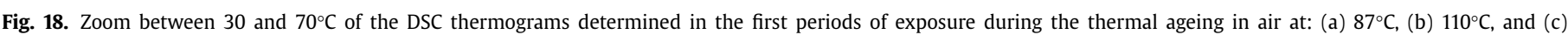
$130^{\circ} \mathrm{C}$ in Fig. 15.

Table 3

Concentration of AO crystals $[\mathrm{AO}]_{\text {insol }}$ estimated by DSC for the heterogeneously stabilised Si-XLPE film during its thermal ageing under air at $87^{\circ} \mathrm{C}, 110^{\circ} \mathrm{C}$, and $130^{\circ} \mathrm{C}$.

\begin{tabular}{|c|c|c|c|c|c|}
\hline \multicolumn{2}{|l|}{$\mathrm{T}=87^{\circ} \mathrm{C}$} & \multicolumn{2}{|l|}{$\mathrm{T}=110^{\circ} \mathrm{C}$} & \multicolumn{2}{|l|}{$\mathrm{T}=130^{\circ} \mathrm{C}$} \\
\hline Ageing time (days) & {$[\mathrm{AO}]_{\text {insol }}\left(\mathrm{mol} . \mathrm{L}^{-1}\right)$} & Ageing time (days) & {$[\mathrm{AO}]_{\mathrm{insol}}\left(\mathrm{mol} . \mathrm{L}^{-1}\right)$} & Ageing time (days) & {$[\mathrm{AO}]_{\text {insol }}\left({\left.\mathrm{mol} . \mathrm{L}^{-1}\right)}^{-1}\right.$} \\
\hline 0 & $(2.4 \pm 0.4) \times 10^{-2}$ & 0 & $(2.4 \pm 0.4) \times 10^{-2}$ & 0 & $(2.4 \pm 0.4) \times 10^{-2}$ \\
\hline 144 & $(2.0 \pm 0.2) \times 10^{-2}$ & 108 & $(6.1 \pm 0.1) \times 10^{-3}$ & 31 & $(6.0 \pm 0.1) \times 10^{-3}$ \\
\hline 288 & $(7.6 \pm 0.1) \times 10^{-4}$ & 213 & i & 71 & $(4.5 \pm 0.1) \times 10^{-3}$ \\
\hline 307 & i & - & - & 100 & i \\
\hline
\end{tabular}

resulting from the $\mathrm{AO}$ chemical consumption. Another interesting observation is the shift of the initial IR bands of the phenol and ester functions of Irganox $1076 \AA$ during this first ageing stage. This spectral modification was already observed in a previous study on the same material but after thermal treatment under primary vacuum at $70^{\circ} \mathrm{C}$ [29]. In fact, the material under study contains 2.1 wt\% of Irganox $1076 \AA$, in which one part of $\mathrm{AO}$ is solubilised into the polymer matrix and the second part of $\mathrm{AO}$ is exuded under the form of crystals. As reminded in Table 1, it was shown in this previous study that the position of the IR bands of the phenol and ester functions is different depending on the physical state of $\mathrm{AO}$ in the polymer matrix (i.e. solubilised or crystallised), but also depending on its crystalline structure. Here, it appears that the IR bands of the phenol and ester functions are initially centred at 3642 and $1736 \mathrm{~cm}^{-1}$, respectively. They thus correspond to the crystalline Form I. Then, as the thermal ageing proceeds, a shift of these two IR bands towards $3649 \mathrm{~cm}^{-1}$ and $1741 \mathrm{~cm}^{-1}$, respectively, can be observed. According to Table 1, these two new positions correspond to $\mathrm{AO}$ dissolved in $\mathrm{PE}$ (i.e. in dispersed state). Consequently, this shift could be due to a decrease of AO crystals concentration during thermal ageing and/or an increase in the soluble fraction of $\mathrm{AO}$ into the polymer matrix. Possible explanations could be a further solubilisation of $\mathrm{AO}$ into the polymer matrix favoured by the sample exposure to higher temperatures (the melting point of $\mathrm{AO}$ crystals is about $50^{\circ} \mathrm{C}$ ), and/or a faster depletion of AO crystals due to physical loss and chemical consumption.

As the thermal ageing proceeds, it can be seen a continuous decrease in the IR bands of the phenol and ester functions of AO at $3648 \mathrm{~cm}^{-1}$ and $1740 \mathrm{~cm}^{-1}$, respectively. In addition, for the two highest temperatures of exposure $\left(110\right.$ and $\left.130^{\circ} \mathrm{C}\right)$, new IR bands already observed in ATR mode appear in the carbonyls region around $1738 \mathrm{~cm}^{-1}, 1770 \mathrm{~cm}^{-1}$, and $1790 \mathrm{~cm}^{-1}$. As previously mentioned, these new IR bands are due to polymer oxidation, as they were also observed during the thermal ageing of the pure Si-XLPE, but also during the thermal ageing of the Si-XLPE stabilised with a thiopropionate AO [37]. Finally, after 403 days of exposure at the highest temperature $\left(130^{\circ} \mathrm{C}\right)$, the IR bands that have appeared in the carbonyls region begin to saturate, while new IR bands appear at $3550 \mathrm{~cm}^{-1}$ and between $3500-3200 \mathrm{~cm}^{-1}$ in the hydroxyls region. According to literature, these latter are due to hydroperoxides species (free and $\mathrm{H}$-bonded $\mathrm{OH}$ ) [66]. It should be remembered that these hydroperoxide species were also detected by DSC analysis (exothermic peak between 130 and $220^{\circ} \mathrm{C}$ ) in Fig. 15 c.

The total concentrations of phenol and ester functions of $\mathrm{AO}$ were determined by FTIR spectroscopy in transmission mode using Eq. 1 and the calibration curves reported in our previous publications [29,33]. As for the homogenously stabilised Si-XLPE, the concentrations of quinone methides (IR band at $1633 \mathrm{~cm}^{-1}$ ) and cinnamates (IR band at $1720 \mathrm{~cm}^{-1}$ ) were also estimated. The resulting concentrations have been plotted against time of exposure at the three temperatures under investigation in Fig. 20a, Fig. 20b, and Fig. 20c. As for the homogenously stabilised Si-XLPE, three kinetic regimes can clearly be distinguished.

i) In the first regime, there is a decrease of both the phenol and ester functions of $\mathrm{AO}$, presumably due to the physical loss of AO through evaporation and/or its chemical consumption. Meanwhile, an initial increase in the concentration of both quinone methides and cinnamates is observed (after which their concentrations remain relatively constant), thus confirming the chemical consumption of AO. It is also noteworthy that the higher the exposure temperature, the higher the concentration of quinone methides and cinnamates. However, the concentration of quinone methides never exceeds $5 \times 10^{-3} \mathrm{~mol} . \mathrm{L}^{-1}$, while the decrease in the concentration of the phenol functions of $\mathrm{AO}$ is much higher, typically about $2 \times 10^{-2}$ mol. $\mathrm{L}^{-1}$ after 100 days of exposure at $130^{\circ} \mathrm{C}$. As previously concluded for the homogeneously stabilised sample, in this first regime, although some degradation products of $\mathrm{AO}$ resulting from its chemical consumption are detected, AO depletion is essentially due to physical loss by evaporation.

ii) In the second regime only observed at $110^{\circ} \mathrm{C}$ and $130^{\circ} \mathrm{C}$ (never reached at $87^{\circ} \mathrm{C}$ for the exposure duration under study), the concentration of quinone methides decreases, while the concentration of cinnamates starts to slightly increase. Meanwhile, the concentration of phenols decreases further, but the concentration of saturated ester functions 

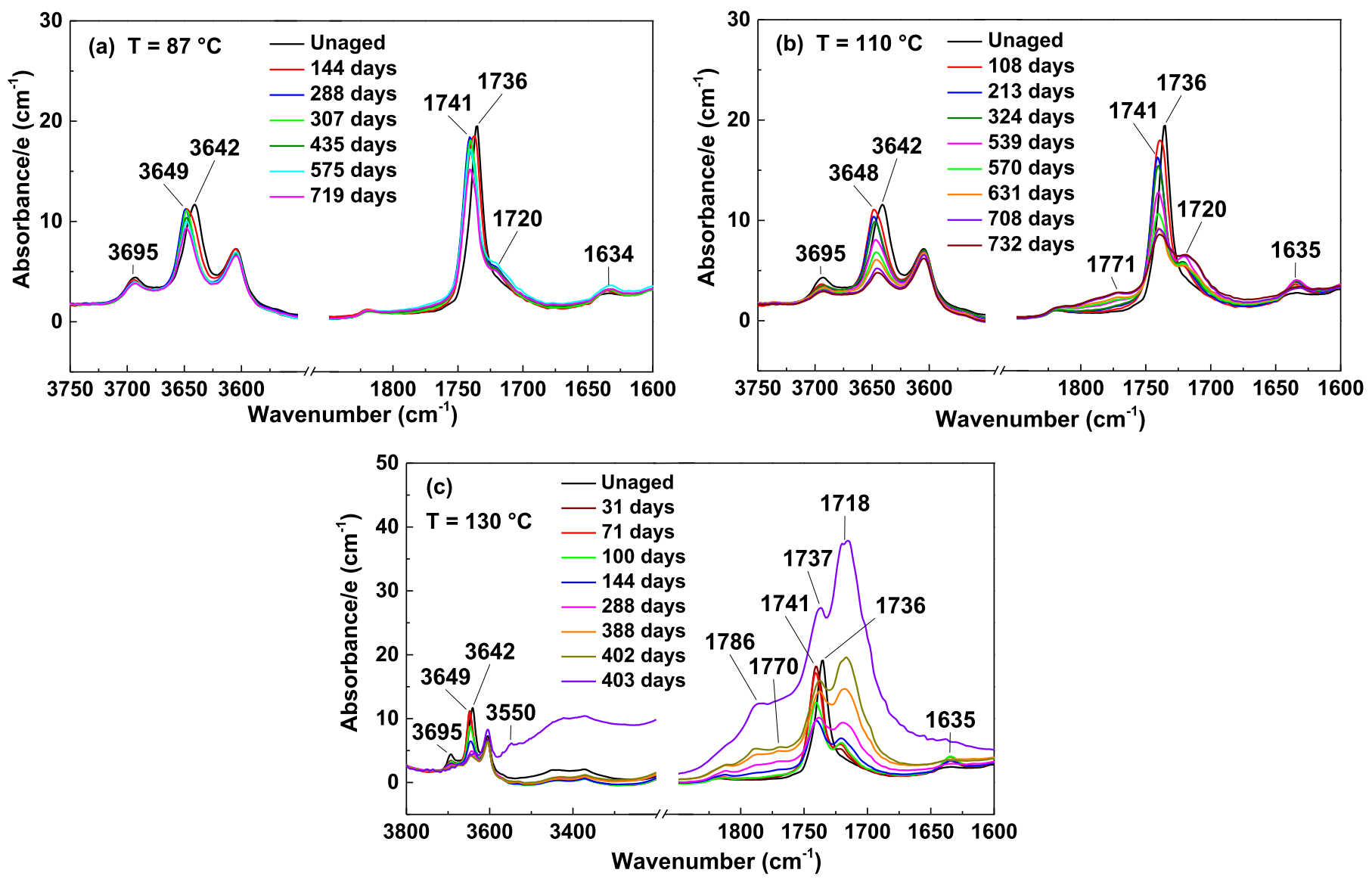

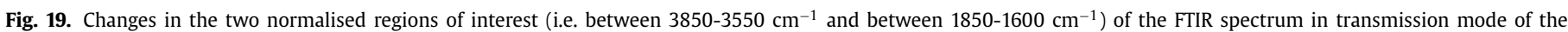
Si-XLPE stabilised with $2.1 \mathrm{wt} \%$ of Irganox $1076 \circledast$ during its thermal ageing in air: (a) at $87^{\circ} \mathrm{C}$, (b) at $110^{\circ} \mathrm{C}$, and $(\mathrm{c})$ at $130^{\circ} \mathrm{C}$.
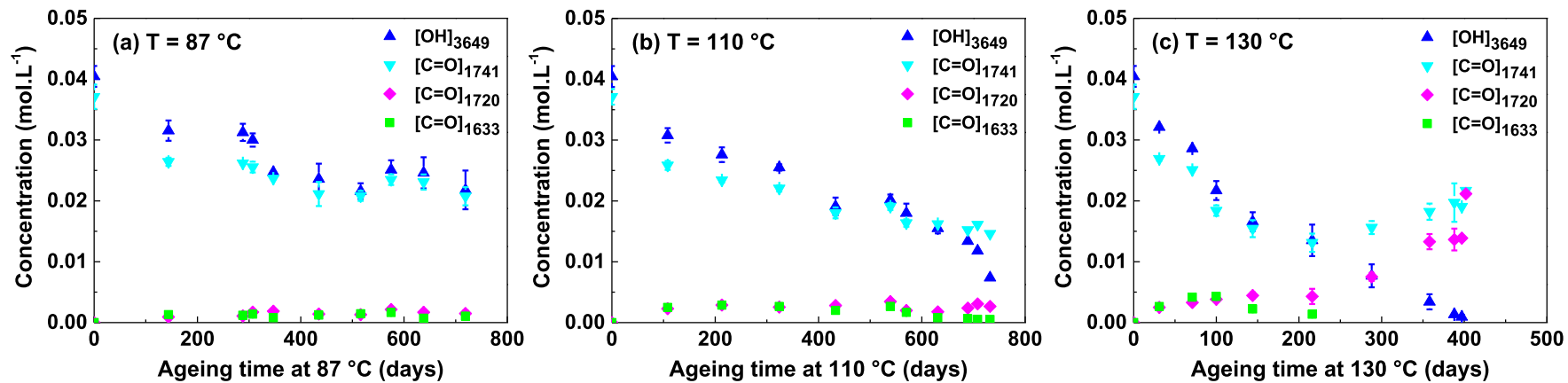

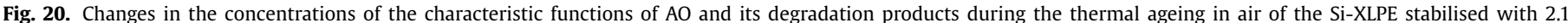
wt\% of Irganox $1076 \circledast$ at: (a) $87^{\circ} \mathrm{C}$, (b) $110^{\circ} \mathrm{C}$, and (c) $130^{\circ} \mathrm{C}$. ( $\left.\mathbf{\Delta}\right)$ phenols, ( $\mathbf{v}$ ) esters, ( $\bullet$ cinnamates, and ( $\left.\mathbf{\square}\right)$ quinones.

(IR band at $1741 \mathrm{~cm}^{-1}$ ) remains relatively constant. The same behaviour was previously observed for the homogeneously stabilised sample at $130^{\circ} \mathrm{C}$, which was presumably due to either the transformation of quinone methides into cinnamates and/or the formation of alkylperoxycyclohexadienones from the reaction between $A O$ and the peroxyl radicals resulting from polymer oxidation. Interestingly, for the two highest temperatures of exposure (i.e. at $110^{\circ} \mathrm{C}$ and $130^{\circ} \mathrm{C}$ ), this second regime seems to be observed when the AO concentration is about $1.3 \times 10^{-2} \mathrm{~mol} . \mathrm{L}^{-1}$, which approximately corresponds to a loss of about $70 \%$ of the initial AO concentration. It should be mentioned that a second regime for a loss of about $75 \%$ of the initial AO concentration was also reported by Tireau et al. [62] for the thermal ageing in air at temperatures ranged between 40 and $80^{\circ} \mathrm{C}$ for a HDPE stabilised with Irganox 1010 (phenolic $\mathrm{AO})$.

iii) Then, as the thermal ageing proceeds further at $130^{\circ} \mathrm{C}$, a third regime is detected. In this last regime, both the concentration of esters and cinnamates increase while the concentration of phenols is still decreasing with the time of exposure. These apparent increases in the saturated esters (IR band at $1741 \mathrm{~cm}^{-1}$ ) and cinnamates (IR band around 1720 $\mathrm{cm}^{-1}$ ) are probably due to the formation of polymer oxidation products, which can overlap the IR bands of the esters and cinnamates as they absorb in the same spectral range. In contrast, the decrease in the concentration of phenols is due to $\mathrm{AO}$ depletion. It is also noteworthy that this last regime is observed when the concentration of active $\mathrm{AO}$ is relatively low, typically about $3 \times 10^{-3}$ mol. $\mathrm{L}^{-1}$ after 360 days of expo- 
sure at $130^{\circ} \mathrm{C}$, which corresponds to a loss of about $90 \%$ of the initial AO concentration. The formation of very small IR bands of oxidation products (in particular, ketones at 1718 $\mathrm{cm}^{-1}$ ) was already detected during the thermal ageing in air at temperatures between $87^{\circ} \mathrm{C}$ and $130^{\circ} \mathrm{C}$ of the Si-XLPE stabilised with a thiodipropionate AO. In particular, oxidation products were observed when OIT at $195^{\circ} \mathrm{C}$ is relatively low: typically about 20 min, which corresponds to a residual concentration of active functions of $\mathrm{AO}$ (i.e. sulphides in that case) of about $10^{-3}$ mol. $\mathrm{L}^{-1}$. However, the detected concentration of ketones was still relatively low (about $10^{-3}-10^{-2}$ mol. $\mathrm{L}^{-1}$ ), thus suggesting the first signs of the polymer oxidation [37]. In addition, for PE stabilised with Irganox 1076®, Moisan and Lever [70] also observed the appearance of oxidation products (IR band of ketones at $1720 \mathrm{~cm}^{-1}$ ) although $\mathrm{AO}$ were still present in the material. Here again, the concentrations of detected oxidation products were very low. These results hence suggest that the polymer oxidation is starting although few AO are still present in the material, which seems to indicate a heterogeneous oxidation of the polymer matrix.

Finally, after 403 days of exposure in air at $130^{\circ} \mathrm{C}$, OIT value at $205^{\circ} \mathrm{C}$ is zero, i.e. no more active AO is present in the Si-XLPE sample. Thenceforth, hydroperoxide species start to be detected (both by FTIR spectroscopy and DSC analysis), and the FTIR spectra (in transmission mode) in the carbonyls region start to saturate. This bands saturation is to be related to the significant increase in the normalised absorbance of carbonyl species measured by FTIR spectroscopy in ATR mode and the significant decrease in the crystallinity ratio of Si-XLPE detected by DSC analysis, both suggesting a catastrophic auto-acceleration of the polymer oxidation. For the two lowest temperatures (i.e. at $87^{\circ} \mathrm{C}$ and $110^{\circ} \mathrm{C}$ ), however, even after 700 days of exposure, no significant sign of polymer oxidation is still detected.

\subsubsection{Analysis after removal of antioxidant crystals at the sample surface}

3.3.4.1. Surface analysis (FTIR spectroscopy in ATR mode). To check the validity of the assumption, whereby a further solubilisation of $\mathrm{AO}$ is occurring during the thermal ageing in air at high temperature, the surface of some aged samples was cleaned using acetone in order to remove the exuded AO crystals. In our previous study [33], it was indeed shown that all AO in excess were exuded at the sample surface and that surface cleaning with acetone is an efficient method to remove all the AO crystals. This treatment will hence enable to characterize only the dissolved AO through the same experimental methodology used until then.

In Fig. 21 are shown the FTIR spectra obtained in ATR mode (i.e. on sample surface) of the heterogeneously stabilised sample aged in air at $130^{\circ} \mathrm{C}$, before and after its surface cleaning with acetone. It can be observed that, after surface cleaning, no more IR bands of phenol and ester functions of $\mathrm{AO}$ and its degradation products (i.e. quinone methides at $1636 \mathrm{~cm}^{-1}$, and cinnamates at $1718 \mathrm{~cm}^{-1}$ ) were detected. This results hence suggest that all the AO crystals, and all the degradation products of AO formed at the sample surface, were well removed by cleaning surface with acetone.

3.3.4.2. Bulk analysis (FTIR spectroscopy in transmission mode). In Fig. 22, are shown the FTIR spectra obtained in transmission mode (i.e. analysis of the whole thickness) of the same thermally aged samples, before and after surface cleaning with acetone. As expected, after surface cleaning, there is a decrease in the absorbance of the IR bands of AO, due to the removal of AO crystals from the sample surface, thus leaving only the AO dissolved in the polymer matrix, as already observed in our previous work [33]. Moreover, it can be observed that, after surface cleaning, the IR bands of both the phenol and ester functions of $\mathrm{AO}$ are more intense for the aged samples than for the unaged sample, thus suggesting a further dissolution of AO crystals into the polymer matrix during thermal exposure. In fact, at ambient temperature, the sample stabilised with $2.1 \mathrm{wt} \%$ of Irganox 1076® was well above the solubility threshold of $\mathrm{AO}$ in the polymer matrix (which was found to be about $1.6 \times 10^{-2}$ mol. $\mathrm{L}^{-1}$ in our previous work [29]), meaning that a high concentration of AO was in excess and under the form of AO crystals exuded at the sample surface. It should be recalled that the AO solubility in a polymer matrix is an increasing function of temperature $[27,71,72]$, which means that the solubility threshold of AO is necessarily higher during thermal exposure at $130^{\circ} \mathrm{C}$ than at ambient temperature. It should also not be forgotten that, at this temperature, both $\mathrm{AO}$ and polymer are melted, which also promotes the further dissolution of $\mathrm{AO}$ as these latter are only soluble in the polymer amorphous phase.

In addition, as $\mathrm{AO}$ are only soluble in the polymer amorphous phase, an increase in the fraction of the polymer amorphous phase should result in a further dissolution of $\mathrm{AO}$ into the polymer matrix. In fact, here, and in particular for thermal ageing at $130^{\circ} \mathrm{C}$, a decrease in the polymer crystallinity ratio was observed during the first stage of the thermal exposure, which could thus have induced the slight increase in the dissolved AO concentration. Furthermore, a last explanation for this increase would involve a progressive modification of the global polarity of the samples due to the formation of oxidation products (polar species) from AO and/or polymer during thermal exposure.

Finally, in Fig. 22, it can also be noticed that, after surface cleaning, the absorbance of the IR bands of quinones and cinnamates decreases slightly, but that these two degradation products of AO are still present. It should be recalled that the quinones and cinnamates detected after thermal exposure on the sample surface were all removed by surface cleaning (Fig. 21). Therefore, the observed decrease in these two IR bands is just due to the removal of the degradation products of AO from the sample surface. It can be thus concluded that the remaining quinones and cinnamates are dissolved in the sample bulk.

Table 4 compiles the total concentrations of AO (i.e. both dissolved and crystallised) and the concentrations of AO crystals estimated by FTIR spectroscopy and DSC for the heterogeneously stabilised sample before and after thermal ageing in air at $130^{\circ} \mathrm{C}$, and before and after surface cleaning with acetone.

The results are quite consistent with a further solubilisation of AO crystals into the polymer matrix during thermal exposure, as the concentration of dissolved $\mathrm{AO}$ in the polymer matrix (i.e. determined by FTIR spectroscopy after surface cleaning) was higher during than before the first stage of thermal exposure. In addition, the differences between the AO concentrations determined before and after surface cleaning (by FTIR spectroscopy) are very close to the concentrations of AO crystals (determined by DSC analysis). It should also be pointed out that, after 100 days in air at $130^{\circ} \mathrm{C}$, no more AO crystals were detected by DSC analysis (i.e. only dissolved $\mathrm{AO}$ were present), and that a similar concentration of AO was determined (by FTIR spectroscopy) for the sample aged for 71 days in air at $130^{\circ} \mathrm{C}$ after surface cleaning. During the exposure at high temperature, the $\mathrm{AO}$ in excess can hence also participate to the stabilisation process as they can further solubilise into the polymer matrix, ultimately resulting into a quasi-homogeneous distribution of $\mathrm{AO}$.

For the two lower temperatures under investigation (i.e. at $87^{\circ} \mathrm{C}$ and $110^{\circ} \mathrm{C}$ ), the surface cleaning was not performed. However, similar results can be suspected as the total concentration of AO (determined by FTIR spectroscopy in transmission mode) in aged sam- 

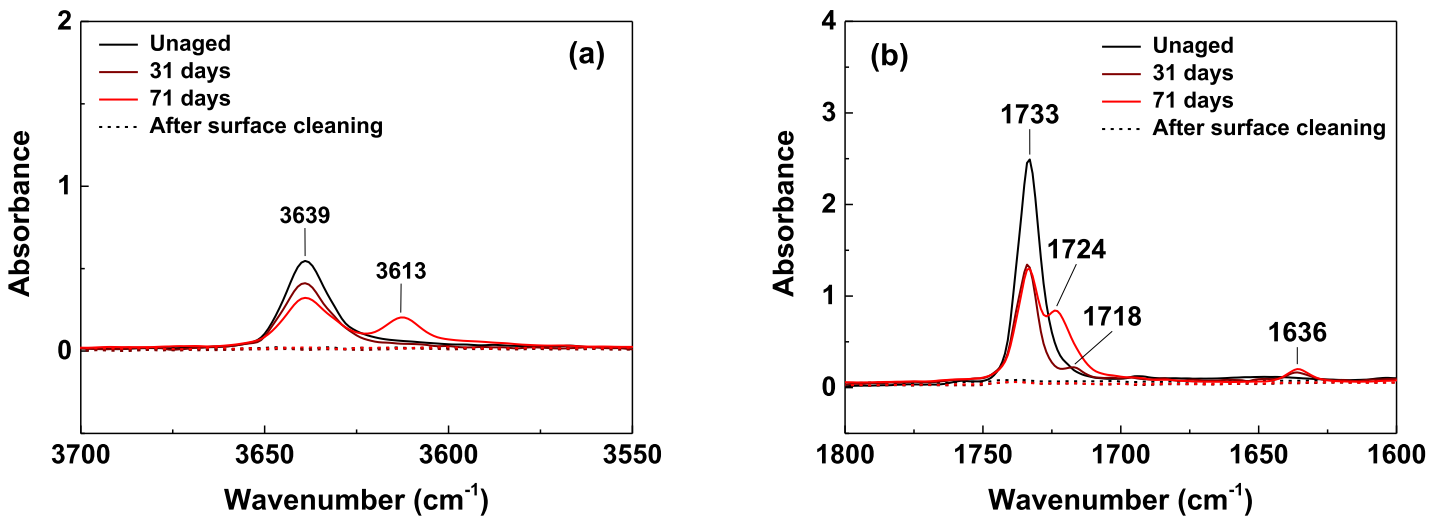

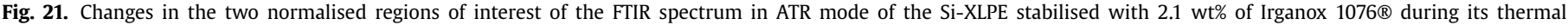
ageing at $130^{\circ} \mathrm{C}$ in air, before (solid lines) and after surface cleaning with acetone (dashed lines): (a) between $3700-3550 \mathrm{~cm}^{-1}$ and (b) between $1800-1600 \mathrm{~cm}^{-1}$.
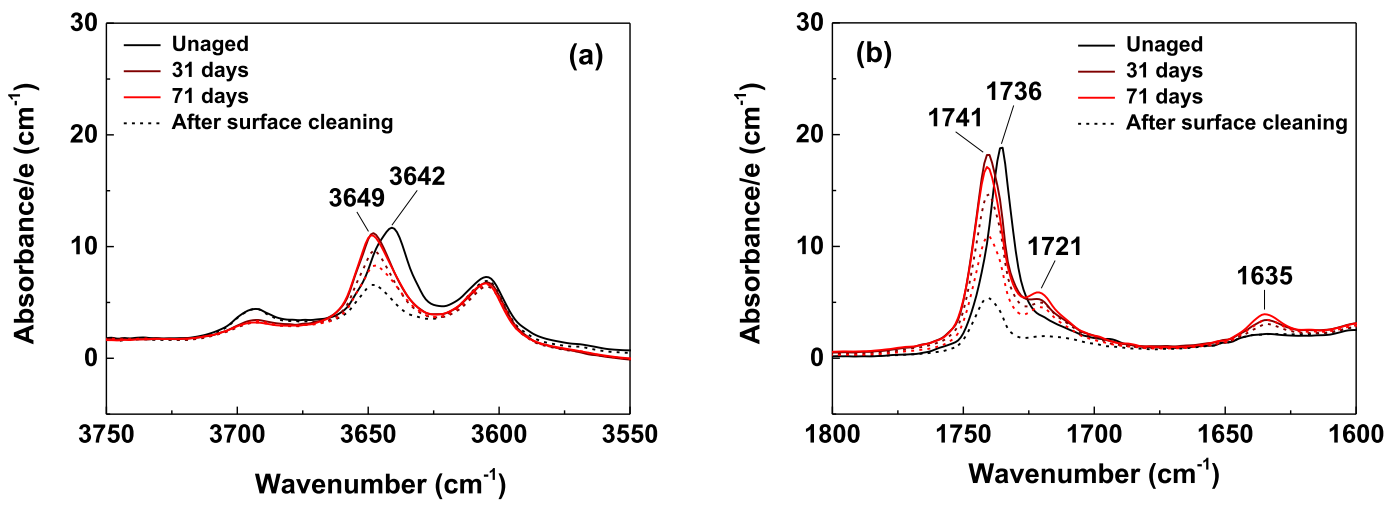

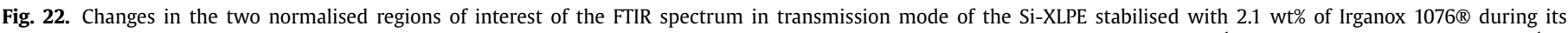
thermal ageing at $130^{\circ} \mathrm{C}$ in air, before (solid lines) and after surface cleaning with acetone (dashed lines): (a) between $3750-3550 \mathrm{~cm}^{-1}$ and (b) between $1800-1600 \mathrm{~cm}^{-1}$.

Table 4

Concentration of AO estimated by FTIR and DSC for the heterogeneously stabilised Si-XLPE film during its thermal ageing under air at $130^{\circ} \mathrm{C}$, before and after surface cleaning with acetone.

\begin{tabular}{|c|c|c|c|}
\hline Sample & & $\begin{array}{l}\text { FTIR (Transmission) } \\
{[\mathrm{AO}]_{\text {tot }}\left(\mathrm{mol.L}^{-1}\right)} \\
\text { (from phenol IR band) }\end{array}$ & $\begin{array}{l}\operatorname{DSC}\left(\mathrm{N}_{2}\right) \\
{[\mathrm{AO}]_{\text {insol }}\left(\mathrm{mol}_{\mathrm{L}} \mathrm{L}^{-1}\right)}\end{array}$ \\
\hline Unaged & $\begin{array}{l}\text { No surface cleaning } \\
\text { After surface cleaning }\end{array}$ & $\begin{array}{l}(4.1 \pm 0.2) \times 10^{-2} \\
(1.6 \pm 0.1) \times 10^{-2}\end{array}$ & $(2.4 \pm 0.4) \times 10^{-2}$ \\
\hline After 31 days at $130^{\circ} \mathrm{C}$ & $\begin{array}{l}\text { No surface cleaning } \\
\text { After surface cleaning }\end{array}$ & $\begin{array}{l}(3.2 \pm 0.1) \times 10^{-2} \\
(2.6 \pm 0.1) \times 10^{-2}\end{array}$ & $(6.0 \pm 0.1) \times 10^{-3}$ \\
\hline After 71 days at $130^{\circ} \mathrm{C}$ & $\begin{array}{l}\text { No surface cleaning } \\
\text { After surface cleaning }\end{array}$ & $\begin{array}{l}(2.9 \pm 0.1) \times 10^{-2} \\
(2.1 \pm 0.1) \times 10^{-2}\end{array}$ & $(4.5 \pm 0.1) \times 10^{-3}$ \\
\hline After 100 days at $130^{\circ} \mathrm{C}$ & No surface cleaning & $(2.2 \pm 0.2) \times 10^{-2}$ & 1 \\
\hline
\end{tabular}

Table 5

Concentration of AO estimated by FTIR and DSC for the heterogeneously stabilised Si-XLPE film during its thermal ageing under air at $87^{\circ} \mathrm{C}$ and $110^{\circ} \mathrm{C}$.

\begin{tabular}{|c|c|c|}
\hline Sample & $\begin{array}{l}\text { FTIR (Transmission) } \\
{[\mathrm{AO}]_{\text {tot }}\left(\mathrm{mol}^{-1} \mathrm{~L}^{-1}\right)} \\
\text { (from phenol IR band) }\end{array}$ & $\begin{array}{l}\operatorname{DSC}\left(\mathrm{N}_{2}\right) \\
{[\mathrm{AO}]_{\text {insol }}} \\
\left(\mathrm{mol} . \mathrm{L}^{-1}\right)\end{array}$ \\
\hline After 307 days at $87^{\circ} \mathrm{C}$ & $(3.0 \pm 0.1) \times 10^{-2}$ & 1 \\
\hline After 213 days at $110^{\circ} \mathrm{C}$ & $(2.8 \pm 0.2) \times 10^{-2}$ & i \\
\hline
\end{tabular}

ples, where no more AO crystals are no longer detected (both by DSC and FTIR spectroscopy in ATR mode), is also higher than the concentration of dissolved $\mathrm{AO}$ in the unaged sample $\left(1.6 \times 10^{-2}\right.$ mol. $\mathrm{L}^{-1}$ ), as shown in Table 5 .

\section{Conclusion}

The thermal ageing in air between 87 and $130^{\circ} \mathrm{C}$ of a Si-XLPE stabilised with an excess of phenolic antioxidant (Irganox 1076®) was investigated using several complementary techniques. Given the microstructural complexity of the material, which contains both dissolved and crystallised AO, simpler materials were first investigated to separate and elucidate the behaviour of pure AO crystals and dissolved AO in the Si-XLPE matrix.

The thermal ageing in air at $130^{\circ} \mathrm{C}$ of the pure AO crystals was investigated using the as-received commercial powder. Through FTIR spectroscopy analysis, several chemical changes were detected. Along with the decrease of the AO IR bands, presumably due to AO evaporation, appearance of new IR bands were also rapidly detected. In the carbonyls region, the new IR bands were 
mainly assigned to quinone methide and cinnamate species, resulting from the chemical consumption of AO. In contrast, in order to explain the appearance of new IR bands in the hydroxyls region, although the polymorphism of Irganox 1076® could not be confirmed by FTIR spectroscopy, a modification of intermolecular interactions involving the phenol functions was also considered.

The FTIR analysis of the thermal ageing in air at $130^{\circ} \mathrm{C}$ of the homogeneously stabilised Si-XLPE showed the formation of the same oxidation products as observed for the pure AO crystals: quinone methides and cinnamates, then confirmed by UV spectroscopy. For this sample, three main kinetic regimes were observed for AO depletion. In the first regime, AO depletion seems to be mainly due to its physical loss through evaporation, even if some traces of degradation products (quinone methides and cinnamates) resulting from its chemical consumption were also detected. In the second regime, as the AO is still depleting, a broadening of the carbonyl IR massif was observed, mainly due to the formation of oxidation products of AO. Then, in a last regime, IR bands corresponding to oxidation products of the polymer matrix were clearly detected, without any other apparent sign of polymer oxidation. As soon as the phenolic AO was completely depleted $(\mathrm{OIT}=0)$, high concentrations in hydroperoxides were suddenly detected by DSC, whose the immediate decomposition led to a significant auto-acceleration of the thermal oxidation of the polymer matrix.

In the case of the heterogeneously stabilised sample, a continuous decrease in the concentration of AO crystals was observed in the first stage of thermal exposure, until no more AO crystal was detected. This can indicate a further solubilisation of AO into the polymer matrix, as suggested by the surface cleaning treatment (with acetone) performed on some aged samples. This experiment also showed that the oxidation products of $\mathrm{AO}$ were both present at the sample surface (i.e. both dissolved and crystallised) and in the sample bulk (i.e. only dissolved). At this stage of investigation, it is, however, still difficult to attribute the chemical consumption observed to a precise phase of AO (i.e. dissolved or crystallised).

In terms of global AO depletion, similar behaviours were observed for both the homogenously and heterogeneously stabilised samples, which might indicate that AO crystals can act in a similar manner than dissolved AO during thermal ageing. Indeed, while an oxidation induction period at $130^{\circ} \mathrm{C}$ in air of about 100 days was observed for the homogeneously stabilised sample, it was pushed back to about 400 days for the heterogeneously stabilised sample. This results clearly indicates that $\mathrm{AO}$ in excess efficiently participate to the stabilisation of the polymer matrix, as already observed in our previous work [33]. Further investigations would, however, be needed to check if similar results can also be obtained at lower temperatures of exposure, but also to finally propose a general kinetic model for Si-XLPE stabilisation by an excess of Irganox 1076®.

\section{Declaration of Competing Interest}

The authors declare that they have no known competing financial interests or personal relationships that could have appeared to influence the work reported in this paper.

\section{CRediT authorship contribution statement}

Anne Xu: Methodology, Investigation, Conceptualization, Writing - original draft. Sébastien Roland: Validation, Writing - review \& editing. Xavier Colin: Validation, Writing - review \& editing, Supervision.

\section{Acknowledgments}

This research is part of the European Project "TeaM Cables" aimed at providing to nuclear power plants (NPP) operators a novel methodology for a more efficient and reliable management of the electrical cables ageing, in particular by developing specific experimental and kinetic modelling tools.

The project leading to this application has received funding from the Euratom research and training program 2014-2018 under grant agreement No 755183.

\section{References}

[1] J.W. Martin, R.A. Ryntz, J. Chin, R. Dickie, Service Life Prediction of Polymeric Materials: Global Perspectives, Springer Science \& Business Media, 2008.

[2] N. Khelidj, X. Colin, L. Audouin, J. Verdu, A simplified approach for the lifetime prediction of PE in nuclear environments, Nuclear Instruments and Methods in Physics Research Section B: Beam Interactions with Materials and Atoms 236 (2005) 88-94.

[3] N. Khelidj, X. Colin, L. Audouin, J. Verdu, C. Monchy-Leroy, V. Prunier, Oxidation of polyethylene under irradiation at low temperature and low dose rate. Part I. The case of "pure" radiochemical initiation, Polymer Degradation and Stability 91 (2006) 1593-1597.

[4] X. Colin, C. Monchy-Leroy, L. Audouin, J. Verdu, Lifetime prediction of polyethylene in nuclear plants, Nuclear Instruments and Methods in Physics Research Section B: Beam Interactions with Materials and Atoms 265 (2007) 251-255.

[5] X. Colin, E. Richaud, J. Verdu, C. Monchy-Leroy, Kinetic modelling of radiochemical ageing of ethylene-propylene copolymers, Radiation Physics and Chemistry 79 (2010) 365-370.

[6] X. Colin, B. Fayolle, L. Audouin, J. Verdu, About a quasi-universal character of unstabilised polyethylene thermal oxidation kinetics, Polymer Degradation and Stability 80 (2003) 67-74.

[7] X. Colin, L. Audouin, J. Verdu, Determination of thermal oxidation rate constants by an inverse method. Application to polyethylene, Polymer Degradation and Stability 86 (2004) 309-321.

[8] N. Khelidj, X. Colin, L. Audouin, J. Verdu, C. Monchy-Leroy, V. Prunier, Oxidation of polyethylene under irradiation at low temperature and low dose rate. Part II. Low temperature thermal oxidation, Polymer Degradation and Stability 91 (2006) 1598-1605.

[9] X. Colin, B. Fayolle, L. Audouin, J. Verdu, The classical kinetic model for radical chain oxidation of hydrocarbon substrates initiated by bimolecular hydroperoxide decomposition, International Journal of Chemical Kinetics 38 (2006) 666-676.

[10] E. Richaud, X. Colin, B. Fayolle, L. Audouin, J. Verdu, Induction period in the low-temperature thermal oxidation of saturated hydrocarbons: Example of polyethylene, International Journal of Chemical Kinetics 40 (2008) 769-777.

[11] D.W. van Krevelen, K. te Nijenhuis, Properties of Polymers: Their Correlation with Chemical Structure; their Numerical Estimation and Prediction from Additive Group Contributions, Elsevier, 2009.

[12] E. Linde, L. Verardi, D. Fabiani, U.W. Gedde, Dielectric spectroscopy as a condition monitoring technique for cable insulation based on crosslinked polyethylene, Polymer Testing 44 (2015) 135-142.

[13] B. Fayolle, X. Colin, L. Audouin, J. Verdu, Mechanism of degradation induced embrittlement in polyethylene, Polymer Degradation and Stability 92 (2007) 231-238.

[14] J. Verdu, Vieillissement chimique, Techniques de l'ingénieur, 1990.

[15] T. Seguchi, K. Tamura, A. Shimada, M. Sugimoto, H. Kudoh, Mechanism of antioxidant interaction on polymer oxidation by thermal and radiation ageing, Radiation Physics and Chemistry 81 (2012) 1747-1751

[16] S. Al-Malaika, S. Riasat, C. Lewucha, Reactive antioxidants for peroxide crosslinked polyethylene, Polymer Degradation and Stability 145 (2017) 11-24.

[17] S. Al-Malaika, Perspectives in Stabilisation of Polyolefins, in: A.-C. Albertsson (Ed.), Long Term Properties of Polyolefins, Springer Berlin Heidelberg, Berlin, Heidelberg, 2004: pp. 121-150.

[18] J. Pospíšil, Mechanistic action of phenolic antioxidants in polymers-A review, Polymer Degradation and Stability 20 (1988) 181-202.

[19] J. Pospíšil, Transformations of phenolic antioxidants during the inhibited oxidation of polymers, Pure and Applied Chemistry 36 (1973) 207-232.

[20] J. Pospíšil, Chemical and photochemical behaviour of phenolic antioxidants in polymer stabilization-a state of the art report, Part I, Polymer Degradation and Stability 40 (1993) 217-232.

[21] J. Pospíšil, Chemical and photochemical behaviour of phenolic antioxidants in polymer stabilization: A state of the art report, part II, Polymer Degradation and Stability 39 (1993) 103-115.

[22] Y.G. Hsuan, R.M. Koerner, Antioxidant Depletion Lifetime in High Density Polyethylene Geomembranes, Journal of Geotechnical and Geoenvironmental Engineering 124 (1998) 532-541.

[23] H. Zweifel, Stabilization of Polymeric Materials, Springer Science \& Business Media, 2012.

[24] S. Al-Malaika, Oxidative degradation and stabilisation of polymers, International Materials Reviews 48 (2003) 165-185.

[25] H. Zweifel, R.D. Maier, M. Schiller, Plastics Additives Handbook, Hanser Publications, 2009. 
[26] E. Richaud, J. Verdu, Vieillissement chimique des polymères - Physicochimie de la stabilisation, Techniques de l'ingénieur, 2012.

[27] X. Colin, B. Fayolle, L. Audouin, J. Verdu, Phénomènes de transport des stabilisants dans les polyoléfines - Partie II : Solubilité, Matériaux \& Techniques 91 (2003) 9-14.

[28] J.H. Hildebrand, Solubility of non-electrolytes, Journal of the Society of Chemical Industry 55 (1936) 665-665.

[29] A. Xu, S. Roland, X. Colin, Physico-chemical characterization of the blooming of Irganox $1076 \AA$ antioxidant onto the surface of a silane-crosslinked polyethylene, Polymer Degradation and Stability 171 (2020) 109046.

[30] H.E. Bair, Exudation of an antioxidant additive from thin polyethylene films, Polymer Engineering \& Science 13 (1973) 435-439.

[31] J. Saunier, V. Mazel, C. Paris, N. Yagoubi, Polymorphism of Irganox 1076®: Discovery of new forms and direct characterization of the polymorphs on a medical device by Raman microspectroscopy, European Journal of Pharmaceutics and Biopharmaceutics 75 (2010) 443-450.

[32] M. Nouman, J. Saunier, E. Jubeli, N. Yagoubi, Additive blooming in polymer materials: Consequences in the pharmaceutical and medical field, Polymer Degradation and Stability 143 (2017) 239-252.

[33] A. Xu, S. Roland, X. Colin, Physico-chemical analysis of a silane-grafted polyethylene stabilised with an excess of Irganox 1076®. Proposal of a microstructural model, Polymer Degradation and Stability 183 (2021) 109453.

[34] P. Pagès, Characterization of polymer materials using FT-IR and DSC techniques, Universidade da Coruña, 2005.

[35] K. Möller, T. Gevert, A solid-state investigation of the desorption/evaporation of hindered phenols from low density polyethylene using FTIR and UV spectroscopy with integrating sphere: The effect of molecular size on the desorption, Journal of Applied Polymer Science 61 (1996) 1149-1162.

[36] P.P. Klemchuk, P.-L. Horng, Transformation products of hindered phenolic antioxidants and colour development in polyolefins, Polymer Degradation and Stability 34 (1991) 333-346.

[37] A. Xu, S. Roland, X. Colin, Thermal ageing of a silane-crosslinked polyethylene stabilised with a thiodipropionate antioxidant, Polymer Degradation and Stability 181 (2020) 109276.

[38] J. Saunier, J.-M. Herry, N. Yagoubi, C. Marlière, Exploring complex transitions between polymorphs on a small scale by coupling AFM, FTIR and DSC: the case of Irganox 1076® antioxidant, RSC Advances 7 (2017) 3804-3818.

[39] S. Bensason, J. Minick, A. Moet, S. Chum, A. Hiltner, E. Baer, Classification of homogeneous ethylene-octene copolymers based on comonomer content, Journal of Polymer Science Part B: Polymer Physics 34 (1998) 1301-1315.

[40] K. Sirisinha, S. Chimdist, Comparison of techniques for determining crosslinking in silane-water crosslinked materials, Polymer Testing 25 (2006) 518-526.

[41] K. Molt, D. Ihlbrock, Principles and applications of quality control by near infrared spectroscopy using the example of polymer additives, Fresenius J Anal Chem 348 (1994) 523-529.

[42] R. Navarro, L. Audouin, J. Verdu, Reactions of antioxidants with molecular oxygen. Part II. Isooctyl-3-(3,5-di-tert-butyl-4-hydroxyphenyl)propionate in silicone matrix, Polymer Degradation and Stability 96 (2011) 965-973.

[43] R. Navarro, L. Audouin, J. Verdu, Reactions of antioxidants with molecular oxygen. Part III: Influence of phenolic stabiliser structures on their oxidation in an inert matrix, Polymer Degradation and Stability 96 (2011) 1389-1396.

[44] S. Beißmann, M. Stiftinger, K. Grabmayer, G. Wallner, D. Nitsche, W. Buchberger, Monitoring the degradation of stabilization systems in polypropylene during accelerated aging tests by liquid chromatography combined with atmospheric pressure chemical ionization mass spectrometry, Polymer Degradation and Stability 98 (2013) 1655-1661.

[45] J. Pospı́šil, W.-D. Habicher, J. Pilař, S. Nešpůrek, J. Kuthan, G.-O. Piringer, H. Zweifel, Discoloration of polymers by phenolic antioxidants, Polymer Degradation and Stability 77 (2002) 531-538.

[46] L.V. Samsonova, L. Taimr, J. Pospíšil, Antioxidants and stabilizers. LXVI. Oxidation and photooxidation of methyl- and octadecyl-3-(3,5-di-tert-butyl-4-hydroxyphenyl)propionates. quenching of singlet oxygen, Die Angewandte Makromolekulare Chemie 65 (1977) 197-210.

[47] C. Berthomieu, E. Nabedryk, W. Mäntele, J. Breton, Characterization by FTIR spectroscopy of the photoreduction of the primary quinone acceptor QA in photosystem II, FEBS Letters 269 (1990) 363-367.

[48] B.H. Stuart, Infrared Spectroscopy: Fundamentals and Applications, John Wiley \& Sons, 2004.
[49] A.H. Ali, K.S.V. Srinivasan, Photoresponsive Functionalized Vinyl Cinnamate Polymers: Synthesis and Characterization, Polymer International 43 (1997) 310-316.

[50] N.S. Allen, D. Mallon, A. Timms, A.W. Green, F. Catalina, Synthesis and spectroscopic properties of novel cinnamate derivatives of benzophenone: Photocuring activity versus photodimerization, European Polymer Journal 29 (1993) 533-538

[51] M.St.G. Flett, Intensities of some group characteristic infra-red bands, Spectrochimica Acta 18 (1962) 1537-1556.

[52] M.D. Cruz, L.V. Schoors, K. Benzarti, X. Colin, Thermo-oxidative degradation of additive free polyethylene. Part I. Analysis of chemical modifications at molecular and macromolecular scales, Journal of Applied Polymer Science 133 (2016) 43287.

[53] E. Richaud, L. Audouin, X. Colin, B. Fayolle, J. Verdu, Rôle des hydroperoxydes dans le vieillissement oxydant des matériaux polymères, Mater. Tech. 96 (2008) 27-42.

[54] B. Peters, S.L. Scott, A. Fong Y. Wang A.E. Stiegman, Reexamining the evidence for proton transfers in ethylene polymerization, PNAS 112 (2015) E4160-E4161.

[55] J.R. Nielsen, A.H. Woollett, Vibrational Spectra of Polyethylenes and Related Substances, J. Chem. Phys. 26 (1957) 1391-1400.

[56] J. Rud Nielsen, R.F. Holland, Dichroism and interpretation of the infrared bands of oriented crystalline polyethylene, Journal of Molecular Spectroscopy 6 (1961) 394-418.

[57] G.L. Oliveira, M.F. Costa, Optimization of process conditions, characterization and mechanical properties of silane crosslinked high-density polyethylene, Materials Science and Engineering: A 527 (2010) 4593-4599.

[58] Y.-T. Shieh, T.-H. Tsai, Silane grafting reactions of low-density polyethylene, J. Appl. Polym. Sci. 69 (1998) 255-261.

[59] G.S. Ahmed, M. Gilbert, S. Mainprize, M. Rogerson, FTIR analysis of silane grafted high density polyethylene, Plastics, Rubber and Composites 38 (2009) $13-20$.

[60] E. Richaud, F. Farcas, B. Fayolle, L. Audouin, J. Verdu, Accelerated ageing of polypropylene stabilized by phenolic antioxidants under high oxygen pressure, Journal of Applied Polymer Science 110 (2008) 3313-3321.

[61] J. Lerchová, L. Kotulák, J. Rotschová, J. Pilař, J. Pospíšil, Antioxidants and stabilizers. LXI. Photochemical behavior of transformation products of phenolic antioxidants: 4-tert-butylperoxy-2,5-cyclohexadienone, Journal of Polymer Science: Polymer Symposia 57 (1976) 229-235.

[62] J. Tireau, Propriétés à long terme des gaines de polyéthylène haute densité utilisées pour les ponts à haubans, Thèse de doctorat, Arts et Métiers ParisTech (2011).

[63] E. Richaud, C. Monchy-Leroy, X. Colin, L. Audouin, J. Verdu, Kinetic modelling of stabilization coupled with stabilizer loss by evaporation. Case of dithioester stabilized polyethylene, Polymer Degradation and Stability 94 (2009) 2004-2014.

[64] F.M. Rugg, J.J. Smith, R.C. Bacon, Infrared spectrophotometric studies on polyethylene. II. Oxidation, Journal of Polymer Science 13 (1954) 535547.

[65] J.H. Adams, Analysis of the nonvolatile oxidation products of polypropylene I. Thermal oxidation, J. Polym. Sci. A-1 Polym. Chem. 8 (1970) 1077-1090.

[66] D.J. Carlsson, D.M. Wiles, The Photodegradation of Polypropylene Films. II. Photolysis of Ketonic Oxidation Products, Macromolecules 2 (1969) 587-597.

[67] J. Lacoste, D.J. Carlsson, S. Falicki, D.M. Wiles, Polyethylene hydroperoxide decomposition products, Polymer Degradation and Stability 34 (1991) 309-323.

[68] Q. Pelzer, Étude du vieillissement des isolants synthétiques des câbles moyenne tension "HTA"., These de doctorat, Université Grenoble Alpes (CoMUE, 2019

[69] U.W. Gedde, M. Ifwarson, Molecular structure and morphology of crosslinked polyethylene in an aged hot-water pipe, Polym Eng Sci 30 (1990) $202-$ 210.

[70] J.Y. Moisan, R. Lever, Diffusion des additifs du polyethylene-V: Influence sur le vieillissement du polymère, European Polymer Journal 18 (1982) $407-$ 411.

[71] J.Y. Moisan, Diffusion des additifs du polyéthylène-I: Influence de la nature du diffusant, European Polymer Journal 16 (1980) 979-987.

[72] N.C. Billingham, P.D. Calvert, A.S. Manke, Solubility of phenolic antioxidants in polyolefins, Journal of Applied Polymer Science 26 (1981) 35433555 . 